\title{
Caracterización inmunológica del calostro en un sistema doble propósito y evaluación de cuatro métodos de conservación
}

\section{Immunological characterization of colostrum in dual purpose system and}

\author{
evaluation of four methods of conservation
}

\author{
Hernández Toca Edith Elena ${ }^{1}$; Olaya Beltrán Jorge Eliecer ${ }^{1}$; Parra Arango Jorge \\ Luis $^{2}$ y Martínez Suárez Manuel ${ }^{3}$ \\ ${ }^{1} \mathrm{MVZ}$ Unillanos; ${ }^{2} \mathrm{MV}$. MSc. Programa Regional Pecuario C.I. La Libertad \\ CORPOICA y ${ }^{3} \mathrm{MV}$. Docente Unillanos \\ manuel.martinez@unillanos.edu.co
}

Recibido 20 de Enero 2014, Aceptado 11 de Abril 2014

\section{RESUMEN}

El presente trabajo, hace parte del proyecto de Optimización de la Producción de Carne del Sistema Doble Propósito en los llanos orientales, zona tropical de Colombia, el objetivo fue contribuir en el aprovechamiento del calostro, determinando su calidad inmunológica, en hembras bovinas del sistema de producción doble propósito en un predio del Piedemonte Llanero y establecer el mejor método de conservación para uso estratégico en las primeras horas de vida del ternero. Para esto se realizó una cuantificación diferenciada de concentraciones de inmunoglobulinas $(\mathrm{lg})$ en calostros hasta 10 horas post-parto para establecer el grado de asociación ente las variables físicas, químicas e inmunológicas en calostro. Asimismo, se evaluaron cuatro métodos de conservación de calostro para ser utilizado en las fincas. La concentración Media de $\mathrm{lg}$ totales fue $6.923 \mathrm{mg} / \mathrm{dL}$. Los valores promedio para cada clase de Ig fueron: IgG: $5882 \mathrm{mg} / \mathrm{dL}$. IgG1: 5544 mg/dL. IgG: $338 \mathrm{mg} / \mathrm{dL}$. IgM: $670 \mathrm{mg} / \mathrm{dL}$. Ig A: 370 $\mathrm{mg} / \mathrm{dL}$. La densidad media fue $1.057 \mathrm{mg} / \mathrm{ml}$, materia seca $23.8 \mathrm{~g} / 100 \mathrm{~g}$ de calostro y proteína $13.3 \mathrm{~g} / 100 \mathrm{~g}$ de calostro. El promedio general para gamma glutamil transferasa (GGT) y grasa fue de $730 \mathrm{UI} / \mathrm{L}$ de suero de calostro y $3.78 \mathrm{~g} / 100 \mathrm{~g}$ de calostro respectivamente. Estas dos variables presentaron los coeficientes de 
variación más altos. El pH medio fue 5.95, la media para cenizas fue $1.48 \mathrm{~g} / 100 \mathrm{~g}$ de calostro y para Absorbancia fue $1.07 \%$. Se encontró una correlación positiva $(P<0.01)$ de densidad con concentración de lg totales, IgG2, materia seca, proteína total, cenizas y GGT. De igual manera materia seca esta correlacionada con proteína total y GGT $(P<0.01)$ y ésta a su vez con cenizas $(P<0.01)$ pero al realizar la función de dependencia el modelo no ajusto. Sin embargo, es preciso realizar estudios adicionales similares para establecer modelos, puesto que en estudios internacionales han reportado un valor más alto en la función de dependencia por lo menos en el caso de la concentración de lg totales en función de la densidad del calostro. Los calostros colectados de los dos predios para este estudio demostraron un valor inmunológico de $6923 \mathrm{mg} / \mathrm{dL}$, valor que se encuentra dentro de los reportados en diferentes estudios en lechería especializada de zonas templadas.

Palabras clave: Calostro, inmunoglobulinas, ganadería doble propósito.

\begin{abstract}
This work is part of project Production Optimization System beef and dairy cattle, in the eastern plains tropical zone of Colombia, the aim was to contribute to the use of colostrum, determining their immune quality in bovine females dual-purpose production in an area of the Llanos Foothills and establish the best method of preservation for strategic use in the first hours of life of the calf. For this differentiated quantification of immunoglobulin $(\mathrm{lg})$ concentrations in colostrum was performed up to 10 hours postpartum to establish the degree of association being the physical, chemical and immunological variables in colostrum. Four methods of preservation of colostrum for use on farms were also evaluated. The concentration of total Ig Media was $6,923 \mathrm{mg} / \mathrm{dL}$. The average values for each class of Ig were IgG: $5882 \mathrm{mg} / \mathrm{dL}$. IgG $: 5544 \mathrm{mg} / \mathrm{dL}$. IgG $2338 \mathrm{mg} / \mathrm{dL}$. IgM $670 \mathrm{mg} / \mathrm{dL}$. IgA: 370 $\mathrm{mg} / \mathrm{dL}$. The average density was $1.057 \mathrm{mg} / \mathrm{ml}, 23.8 \mathrm{~g} / 100 \mathrm{~g}$ dry matter and protein colostrum $13.3 \mathrm{~g} / 100 \mathrm{~g}$ colostrum. The overall average for gamma glutmyl
\end{abstract}


transferase (GGT) and milk fat was $730 \mathrm{IU} / \mathrm{L}$ of serum of colostrum and $3.78 \mathrm{~g} / 100$ $\mathrm{g}$ colostrum, respectively. These two variables had coefficients of variation higher. The average $\mathrm{pH}$ was 5.95 , the average ash was $1.48 \mathrm{~g} / 100 \mathrm{~g}$ of colostrum and Absorbance was $1.07 \%$. A positive correlation $(P<0.01)$ was found with density concentration of total $\lg$, $\lg G_{2}$, dry matter, total protein, ash, and GGT. Similarly dry matter is correlated with total protein and GGT $(P<0.01)$ and total protein with ash $(P<0.01)$ but to perform the function of the model is not adjusted dependence. However, it must perform additional similar studies since adjusting said international studies have reported a higher value in the dependency function at least in the case of the concentration of total Ig as a function of the density of the colostrum. The colostrum collected from two farms in this study demonstrated an immunological value of $6923 \mathrm{mg} / \mathrm{dL}$, a value that is within those reported by other studies in temperate dairy specialist.

Keywords: Colostrum, immunoglobulins, beef and dairy cattle.

\section{INTRODUCCIÓN}

En las empresas ganaderas del sistema doble propósito del Piedemonte Llanero, el ternero representa una parte fundamental en la cadena de producción, ya que al destetar animales sanos y con buen peso corporal, se garantiza posteriormente, hembras de reemplazo aptas para la reproducción y machos con buena calidad para el mercado. Además, el ternero determina en gran parte la longitud de la lactancia, considerando que si la cría muere, la vaca interrumpe su lactancia (Flórez, 1998 y Lakritz et al., 2000).

Los terneros que presentan enfermedades el primer mes de vida, no se recuperan completamente y al destete, presentan menor peso que los animales sanos, además tienen un mayor riesgo de enfermedad o muerte, lo que trae pérdidas económicas para la empresa ganadera (Escobar y Bonilla, 1997; Pérez et al. 1990; Sivula, 1996; Virtala, 1996; Wattiaux, 2001). Los terneros que presentan enfermedad clínica o subclínica son menos eficientes en la ganancia de peso y 
más susceptibles a morir, en épocas de escasez de alimento y condiciones ambientales adversas. El deceso del ternero en el primer mes refleja una baja natalidad en los hatos doble propósito, lo que agudiza aún más la problemática, incidiendo directamente en los costos de producción y la rentabilidad de la actividad ganadera (Flórez, 2000).

El ternero nace sin inmunoglobulinas ( $(\mathrm{g})$, las cuales se adquieren a través del consumo de calostro en las primeras horas de vida después del nacimiento, que lo protegen contra patógenos causantes de enfermedad. Cuando el ternero no consume oportunamente una cantidad suficiente de $\lg$ disminuyen las probabilidades de supervivencia, fenómeno conocido como Falla en la Transferencia de Inmunidad Pasiva (FTIP) que está correlacionado positivamente con las tasas de morbi-mortalidad (Parra, 2003).

La placenta bovina no permite el paso de las Ig de la madre al ternero, de modo que deben ser transferidas por medio del calostro y absorbidas por el intestino del ternero. El calostro, contiene las Ig necesarias que le confieren inmunidad a los terneros contra los agentes infecciosos predominantes en su ambiente. El tiempo de ingestión y absorción de lg calostrales es crítica para la supervivencia del ternero neonato. Martínez et al., (2000) determinaron que los terneros que consumieron su primer calostro después de dos horas del parto presentaron 8.24 veces mayor riesgo de enfermar que los terneros que lo consumieron antes de dos horas.

Es necesario tener en cuenta, que a partir del parto la composición del calostro comienza a cambiar gradualmente, pareciéndose cada vez más a la leche, lo que disminuye rápidamente, la concentración de lg. Existe un "cierre" fisiológico progresivo del mecanismo de absorción de las lg, por lo cual el intestino del neonato pierde su capacidad de permeabilidad a las grandes moléculas, siendo casi nula a las 24 horas. En la primera hora de edad, se aprovecha el doble de 
cantidad de lg comparada con las que se absorben a las nueve horas de edad (Perino, et al., 1995; Quigley, 2000).

El amamantamiento es el método natural de suministrar calostro al ternero. Sin embargo, algunos factores pueden interferir con la ingestión de un adecuado volumen, entre los más importantes están las distocias, terneros débiles con incapacidad física para alcanzar la glándula mamaria, agresividad de la vaca hacia su cría, vacas de primer parto que por su falta de experiencia no son buenas madres, en términos de estimular a la cría a que alcance la glándula mamaria, ya que el grado de habilidad materna se correlaciona positivamente con los niveles séricos de lg (Perino, 1997).

En Colombia en sistemas de producción bovina de cría, al menos el 10\% de los terneros mueren antes del año de edad, siendo la mortalidad mayor en terneros menores de dos meses y es en la edad neonatal donde la morbi-mortalidad alcanza una tasa del $31.2 \%$ en explotaciones de la Altillanura Colombiana (López et al., 1998) y $37.54 \%$ en sistemas de cría y doble propósito del Piedemonte del Meta y Casanare (Gómez, 1999).

En el Piedemonte Llanero, los problemas de salud mas prevalentes en terneros son: las diarreas $(62.7 \%)$, las masas umbilicales $(9.3 \%)$, enflaquecimiento progresivo $(7.9 \%)$ y los nacidos débiles $(7.8 \%)$; El porcentaje de morbilidad general es del $41 \%$ y de letalidad del $7.6 \%$ (Parra, 2003). La mortalidad, según estudios de monitoreo en sistemas de producción de cría, demuestra que en el Piedemonte Llanero esta cercana al 15\% (Flórez, 2000). Una manera de contribuir en la prevención de las enfermedades antes mencionadas, es la adecuada ingestión de un buen calostro por parte del ternero al nacimiento.

Esta situación demuestra la magnitud del problema que surge de no realizar una atención oportuna al ternero recién nacido y a los animales enfermos, y de llevar a cabo mejores prácticas de manejo que pueden disminuir las tasas actuales de mortalidad por debajo del 5\%. En Colombia la Falla en la Transferencia de 
Inmunidad Pasiva (FTIP) en terneros del sistema doble propósito se estima entre $14.8 \%$ y $19.6 \%$ (Aricada et al., 2004). También se ha demostrado que los terneros con FTIP presentan nueve veces más probabilidad de enfermarse y hasta 25 veces más probabilidades de morir, que los animales sin FTIP (López et al., 1998); además, los terneros que no consumen calostro en cantidad adecuada muestran bajas tasas de crecimiento y baja ganancia de peso al destete (Robinsón et al., 1998), en las hembras, menor producción de leche en su primera lactancia, además requieren un mayor tiempo para llegar a la etapa reproductiva y aumento en las tasas de descarte. Se ha observado que, si se identifican los terneros con FTIP, las pérdidas económicas por tratamientos médicos y mortalidad disminuyen en forma considerable (Castro y Elizondo, 2012).

Es claro que existe una relación directa entre los bajos niveles de lg séricas alta morbi-mortalidad en terneros, y demás factores que intervienen con la adecuada ingestión de calostro como alteraciones anatómicas de la glándula mamaria, casos de mastitis severa, o inclusive cuando la madre no le proporciona a su cría un calostro de buena calidad. Para prevenir, que dichos eventos interfieran con un normal y eficiente proceso de inmunización natural, se hace necesario disponer de una fuente de calostro de alta calidad para ser suministrada de forma artificial en la cantidad suficiente durante las primeras horas de vida. Así mismo evaluar diferentes métodos de conservación para determinar con cada uno, el tiempo máximo al cual logran mantener las propiedades funcionales del calostro (García, et al., 2006).

Al mejorar los niveles de Ig en los terneros neoantos es posible que el sistema de producción doble propósito mejore la producción de carne y leche con el fin de abastecer el mercado regional principalmente, buscando mejorar la competitividad en la cadena productiva, adoptando alternativas tecnológicas viables, con el fin de generar un mayor beneficio económico, incrementando la rentabilidad, la calidad y la eficiencia. 


\section{METODOLOGÍA}

Los análisis de laboratorio fueron realizados en el Laboratorio de Salud animal del Centro de Investigaciones CORPOICA "La Libertad". El trabajo de campo se desarrolló en un predio del Piedemonte Llanero bajo el Sistema Doble Propósito, en el Municipio de Castilla la Nueva, Departamento del Meta, Colombia, que en promedio ordeña 160 vacas mensuales y provee adecuada cantidad de hembras paridas durante el año para recolectar calostro. La altura es de 300-325 m.s.n.m., la temperatura media anual oscila entre 26.2 y $27^{\circ} \mathrm{C}$, la precipitación anual promedio es $2.891,2 \mathrm{~mm}$., la humedad relativa es del $78 \%$ y un brillo solar de 1.713,4 (horas/año) (IDEAM, 2004).

La investigación se desarrolló en tres fases, la primera fue la determinación de $\operatorname{lgA}$, IgM e lgG2; gamma glutamyl transferasa (GGT) y absorbancia a 72 muestras de calostro desengrasado existentes en el banco de calostro de CORPOICA; la segunda, con la información parcial de las variables (densidad, $\mathrm{pH}$, materia seca, proteína, grasa y cenizas) de los mismos 72 calostros almacenados, fue realizado análisis estadístico y se compararon con los valores obtenidos en la determinación de IgA, IgM e IgG $\mathrm{G}_{2}$ GGT y Absorbancia; y la tercera fue la evaluación de cuatro métodos de conservación de calostro en finca, en la Tabla 1 se presentan las tres fases de las actividades de investigación.

En el laboratorio de Salud Animal "La Libertad", se encontraban almacenados 72 alícuotas de calostro desengrasados y deshidratados, colectados de dos predios. El primer predio fue el mismo donde se colectaron los calostros para la evaluación de cuatro métodos de conservación y el segundo está ubicado en el municipio de Fuente de Oro en el Piedemonte del Meta; estos calostros provienen de vacas doble propósito, tomados en las primeras 10 horas post-parto, de diferentes animales, número de parto y razas, los últimos dos aspectos no se pudieron establecer debido al irregular manejo de los registros de las dos fincas provocado 
por el cambio del personal encargado del manejo de los animales y el nivel de escolaridad de los mismos.

Tabla 1. Fases de investigación para evaluar el calostro de vacas doble propósito y cuatro métodos de conservación

\begin{tabular}{|c|c|c|c|c|}
\hline $\begin{array}{l}\text { Trabajo en } \\
\text { Laboratorio }\end{array}$ & $\begin{array}{c}\text { Banco de } \\
\text { calostro } \\
\text { CORPOICA } \\
\text { (72 } \\
\text { muestras) }\end{array}$ & $\begin{array}{c}\text { Alícuotas } \\
\text { Desengrasadas } \\
\text { Alícuotas } \\
\text { Deshidratadas }\end{array}$ & \multicolumn{2}{|c|}{$\begin{array}{l}\text { - Determinación de } \lg A \text {, } \\
\text { lgM e lgG2. } \\
\text { - Determinación de GGT. } \\
\text { - Absorbancia. } \\
\text { Determinación de proteína } \\
\text { a } 25 \text { alícuotas de las } 72 \text {. }\end{array}$} \\
\hline & \multicolumn{4}{|c|}{$\begin{array}{cl}\begin{array}{c}\text { Colección de } 43 \text { muestras } \\
\text { de calostro }\end{array} & \text { Determinación de: } \\
& \text { Densidad y Materia seca }\end{array}$} \\
\hline $\begin{array}{l}\text { Trabajo en } \\
\text { Campo. }\end{array}$ & $\begin{array}{l}\text { Evaluación } \\
\text { de } 4 \\
\text { métodos de } \\
\text { conservación } \\
\text { de calostro }\end{array}$ & $\begin{array}{l}\text { - Fresco } \\
\text { - Acidificado } \\
\text { - Refrigerado } \\
\text { - Congelado }\end{array}$ & \multicolumn{2}{|c|}{$\begin{array}{l}\text { Determinación a cada } \\
\text { tratamiento de: } \\
\text { - Densidad. } \\
\text { - Materia seca. } \\
\text { - Proteína. } \\
\text { - pH. }\end{array}$} \\
\hline $\begin{array}{c}\text { FASE III } \\
\text { Trabajo } \\
\text { Estadístico. }\end{array}$ & $\begin{array}{l}\text { Banco de } \\
\text { Calostro } \\
\text { Corpoica }(72 \\
\text { muestras) }\end{array}$ & $\begin{array}{l}\text { Valores determinados } \\
\text { parcialmente: } \\
\text { - Densidad. } \\
\text { - Materia seca. } \\
\text { - Proteína. } \\
\text { - Grasa. } \\
\text { - Cenizas. } \\
\text { - pH. } \\
\text { - Densidad. } \\
\text { - Materia seca. } \\
\text { - Proteína. } \\
\text { valuación de } 4 \text { métodos }\end{array}$ & $\begin{array}{l}\text { Análisis de } \\
\text { varianza } \\
\text { para } \\
\text { determinar } \\
\text { el efecto } \\
\text { del tiempo } \\
\text { entre las } \\
\text { mediciones } \\
\text { para } \\
\text { valorarlas } \\
\text { como un } \\
\text { todo } \\
\text { conservació }\end{array}$ & $\begin{array}{c}\text { Correlación } \\
\text { entre las } \\
\text { anteriores } \\
\text { variables con } \\
\text { GGT, } \\
\text { Absorbancia } \\
\text { y } \\
\text { cuantificación } \\
\text { de } \operatorname{lgA} \text {, IgM e } \\
\lg G_{2},\end{array}$ \\
\hline
\end{tabular}

Previo al inicio del trabajo a las 72 muestras de calostros, se les realizó pruebas físicas y químicas encontrando la información consignada en la Tabla 2. Para poder utilizar estas variables, en la investigación fue necesario recolectar 43 muestras del mismo predio donde se evaluaron los cuatro métodos de conservación; determinándoles densidad y materia seca; simultáneamente se 
tomaron de las 72 alícuotas de calostro deshidratado 25 a las cuales no se les había determinado proteína y se les realizó el análisis.

Tabla 2. Resumen de valores, información y alícuotas encontradas al inicio de la investigación

\begin{tabular}{|c|c|c|c|c|}
\hline \multirow{2}{*}{$\begin{array}{c}\text { Prueba } \\
\text { Densidad } \\
\text { (mg/ml) a } \\
15^{\circ} \mathrm{C}\end{array}$} & \multirow{2}{*}{$\begin{array}{c}\text { Método } \\
\text { Lactodensímetro }\end{array}$} & \multirow{2}{*}{$\begin{array}{c}\text { № de } \\
\text { muestras } \\
\text { valoradas }\end{array}$} & \multicolumn{2}{|c|}{$\begin{array}{l}\text { Estado de las Alícuotas y } \\
\text { método para su obtención en } \\
\text { laboratorio }\end{array}$} \\
\hline & & & $\begin{array}{c}\text { Alícuotas } \\
\text { Desengrasadas }\end{array}$ & $\begin{array}{c}\text { Alícuotas } \\
\text { Deshidratadas }\end{array}$ \\
\hline $\begin{array}{c}\text { Materia seca } \\
(\%)\end{array}$ & $\begin{array}{l}\text { Desecación por } \\
\text { calor (55ㄷำ/48 } \\
\text { horas) }\end{array}$ & 72 & & \\
\hline $\mathrm{pH}$ & $\begin{array}{c}\text { Potenciómetro } \\
\text { digital }\end{array}$ & 70 & $\begin{array}{l}\text { Ultracentrifugación } \\
\text { refrigerada }\end{array}$ & $\begin{array}{c}55^{\circ} \mathrm{o} \text { por } 48 \\
\text { horas }\end{array}$ \\
\hline Cenizas (\%) & Mufla & 31 & & \\
\hline Proteína (\%) & Microkjendal & 32 & & \\
\hline Grasa (\%) & Soxhlet. & 39 & & \\
\hline
\end{tabular}

Con estos nuevos valores se hizo un análisis de varianza entre los valores existentes y los obtenidos de densidad, materia seca y proteína, esto con el fin de establecer el efecto del tiempo en la determinación de las variables y de esta forma se tomó la información como un todo, se le corrió estadística descriptiva, y se aprovechó para correlacionarla con las concentraciones de lg, GGT y absorbancia. A las 72 alícuotas de calostro desengrasado se les realizó cuantificación de $\lg A$, $\lg M$ e $\lg G_{2}$ por medio del método de Inmunodifusión Radial Simple, determinación de GGT utilizando el método cinético colorimétrico y absorbancia cuyo instrumento de medida fue el espectrofotómetro a una longitud de onda de $630 \mathrm{~nm}$.

\section{Determinación de $\lg A, \lg M, \lg G$}

Para la cuantificación de la concentración de lg se utilizaron kits comerciales de $\mathrm{ICN}^{\circledR}$ para cada Ig, basados en Inmunodifusión Radial Simple. El kit para la 
determinación de $\operatorname{Ig} A$ contiene tres concentraciones conocidas de $\lg \mathrm{A}(400,250$, $150 \mathrm{mg} / \mathrm{dL}$ ). Para determinar la curva patrón de calibración, teniendo en cuenta la completa difusión de la reacción manifestada en el crecimiento del halo se diluyeron las concentraciones conocidas de $\lg A$ en $(400,200,250,150$ y 75 $\mathrm{mg} / \mathrm{dL}$ ). El fabricante recomienda que para diluir los calibradores o las muestras se debe utilizar solución salina al $0.9 \%$. Del total de muestras del banco de calostro se seleccionaron dos, una con alta concentración de proteína (21\%) y la segunda con baja concentración de proteína (9.56\%) y cada una se diluyó 1:2 y 1:4 respectivamente, de tal forma que para la prueba de estandarización se utilizaron tres alícuotas de cada muestra. (1:1, 1:2 y 1:4); éstas se diluyeron con el fin de establecer el crecimiento de los halos con respecto al de los calibradores. En la placa se depositaron las 5 concentraciones conocidas de $\lg A$ y las 6 alícuotas de calostro que se determinaron a partir de las 2 muestras del banco de calostro. Los halos formados por la unión de Ig y anti-lg dejaron de crecer a las 40 horas, por tal motivo este fue el tiempo de lectura. El crecimiento de los halos de las concentraciones 200 y $250 \mathrm{mg} / \mathrm{dL}$ fue similar, por tal razón solo se dejaron las concentraciones $(400,250,150$ y $75 \mathrm{mg} / \mathrm{dL})$. El crecimiento de los halos de las diluciones de calostro $(1: 1,1: 2$ y 1:4) fue similar, razón por la cual se decidió trabajar con el calostro desengrasado sin dilución (1:1) (Figura 1). El diámetro de los halos fue medido con un nonio (Somet $1 / 20 \mathrm{~mm}$ ).

El kit para la determinación de IgM contiene 4 concentraciones conocidas de $\lg M$ (520, 260, 130 y $60 \mathrm{mg} / \mathrm{dL})$. De forma similar a la IgA se determinó la curva patrón de calibración; se utilizaron las mismas muestras de calostro con sus características y diluciones $(1: 1,1: 2$ y 1:4), se diluyó la última concentración conocida de $\operatorname{IgM}(520,260,130,60$ y $30 \mathrm{mg} / \mathrm{dL})$. El halo formado por la alícuota del calostro desengrasado entero (1:1) tanto de la muestra con alta concentración de proteína y la muestra con baja concentración de proteína, fue indeterminado y de difícil medición; fue necesario diluir las muestras de calostro en (1:2) y la lectura se hizo a las 46 horas post inicio de la prueba (Figura 2). 
El kit ICN Biomedicals ${ }^{\circledR}$ para la cuantificación de lgG, incluye el valor de la proporción de $\lg G_{1}$ e $\lg G_{2}$ en $\lg G$ total, donde $\lg G=\lg G_{1}+\lg G_{2}$. El contenido de $\lg G_{2}$ e $\lg G_{1}$ en $\lg G$ es de $5.74 \%$ y $96.24 \%$ respectivamente bajo este criterio se determinó $\lg G_{1}$ e $\lg G$ total $\left(I C N\right.$ Biomedicals ${ }^{\circledR}$ ). Para la estimación de la curva patrón de calibración se realizó de forma similar a la de $\lg \mathrm{A}$ e $\lg \mathrm{M}$, las concentraciones conocidas de $\operatorname{lgG}_{2}$ fueron de $(120,60,30$ y $15 \mathrm{mg} / \mathrm{dL})$ y se realizó dilución a la última concentración (120, 60, 30, 15 y $7.5 \mathrm{mg} / \mathrm{dL})$. El crecimiento de los halos en la alícuota del calostro entero desengrasado fue desmedido, con lo cual se determinó diluir las muestras en (1:2) y el tiempo de lectura fue de 24 horas pos inicio de la prueba, y se suprime la última dilución de la concentración conocida de $\lg \mathrm{G}_{2}$, debido a que el crecimiento del halo fue similar entre 15 y 7.5 $\mathrm{mg} / \mathrm{dL}$. (Figura 3).

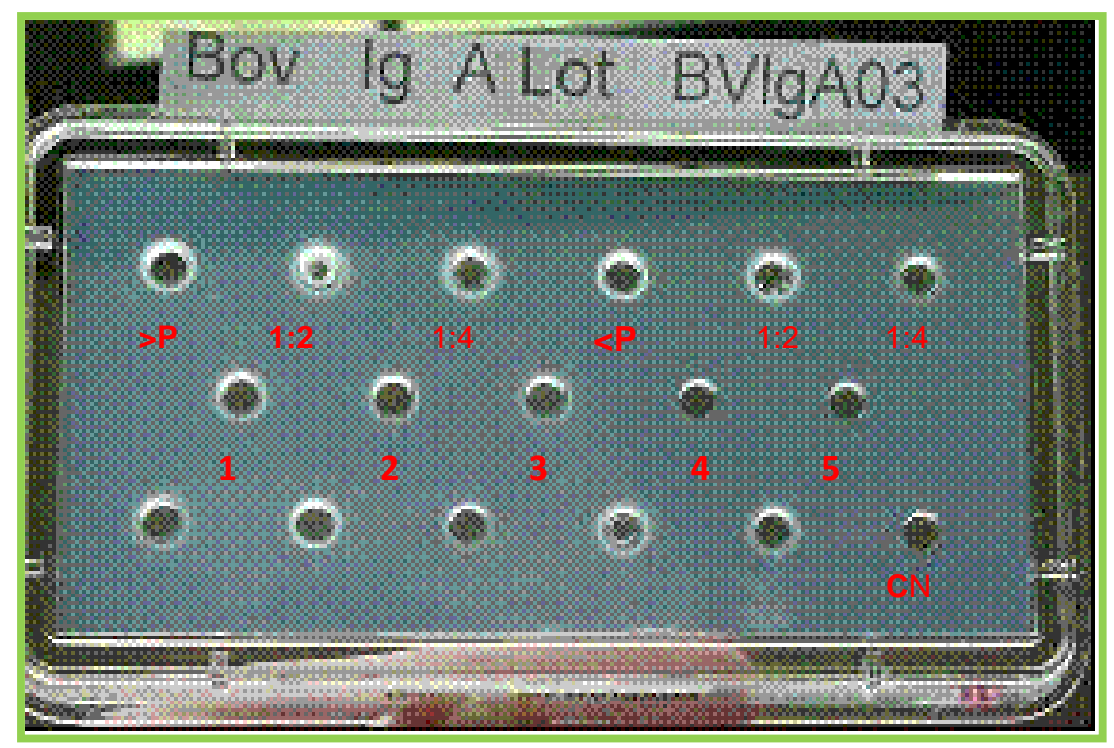

>P: Mayor proteína (21\%) $<$ P: Menor proteína 9.5\% 1: 2 y 1:4 Diluciones 1: $400 \mathrm{mg} / \mathrm{dL}$ 2: $250 \mathrm{mg} / \mathrm{dL}$ 3: $150 \mathrm{mg} / \mathrm{dL}$ 4: $75 \mathrm{mg} / \mathrm{dL}$ CN: Control Negativo (Solución salina $0.9 \%$ )

Figura 1. Inmunodifusión Radial Simple de muestras de calostro desengrasado para la determinación de $\lg A$.

Para medir absorbancia se utilizó un espectrofotómetro marca DYNEX ${ }^{\circledR}$ Labsystems modelo MRX II. Fue necesario realizar varias lecturas con diferentes longitudes de onda, para determinar cuál de ellas proporcionaba una mejor lectura. Sé eligió la longitud de onda de $630 \mathrm{~nm}$. Para la medición de absorbancia 
en la placa para espectrofotómetro se adicionaron dos alícuotas de $100 \mu$ le agua destilada (blanco) y cada una de las 72 muestras de calostro desengrasado (100 $\mu l$ por pozo).

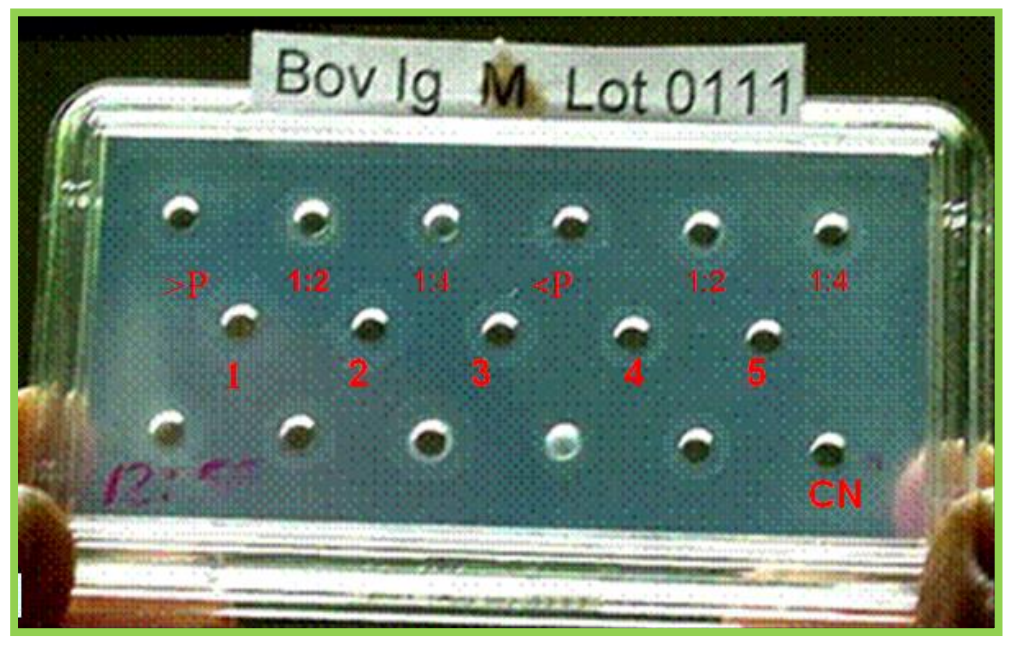

$>$ P: Mayor proteína $(21 \%)$

$<$ P: Menor proteína $9.5 \%$

$1: 2$ y $1: 4$ Diluciones

1: $520 \mathrm{mg} / \mathrm{dL}$

2: $260 \mathrm{mg} / \mathrm{dL}$

3: $130 \mathrm{mg} / \mathrm{dL}$

4: $60 \mathrm{mg} / \mathrm{dL}$

5: $30 \mathrm{mg} / \mathrm{dL}$

CN: Control Negativo

(Solución salina 0.9\%)

Figura 2. Inmunodifusión Radial Simple de muestras de calostro desengrasado para la determinación de lgM.

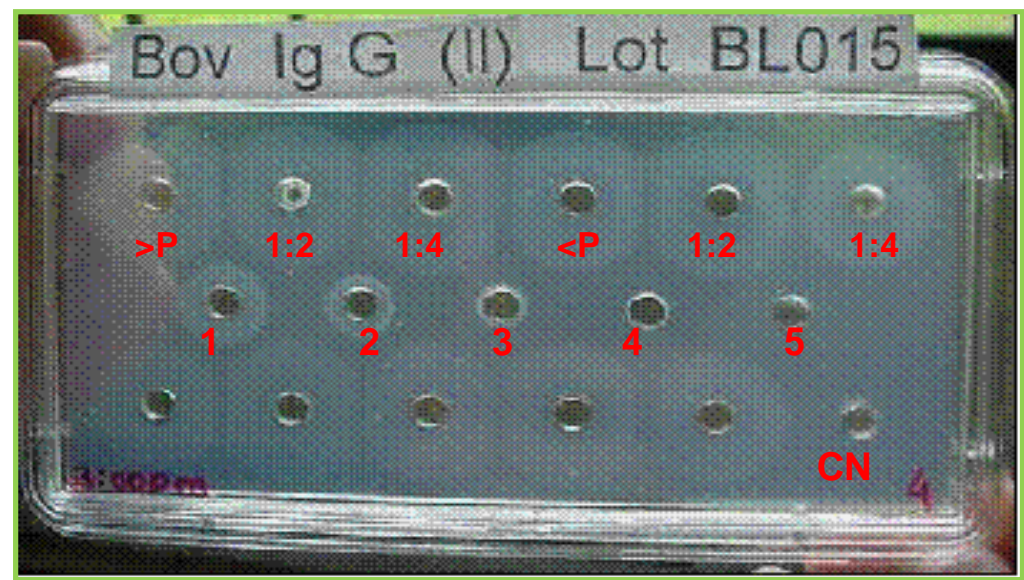

$>\mathrm{P}:$ Mayor proteína

$(21 \%)$

$<$ P: Menor proteína $9.5 \%$

$1: 2$ y $1: 4$ Diluciones

1: $120 \mathrm{mg} / \mathrm{dL}$

2: $60 \mathrm{mg} / \mathrm{dL}$

3: $30 \mathrm{mg} / \mathrm{dL}$

4: $15 \mathrm{mg} / \mathrm{dL}$

5: $7.5 \mathrm{mg} / \mathrm{dL}$

$\mathrm{CN}$ : Control Negativo

(Solución salina 0.9\%)

Figura 3. Inmunodifusión Radial Simple de muestras de calostro desengrasado para la determinación de lgG2.

Para determinar GGT, en una placa de fondo plano para espectrofotómetro se colocaron en dos pozos muestras de agua destilada (blanco), una muestra de reactivo control (suero bovino normal), incluida en el kit y en cada uno de los pozos restantes $200 \mu \mathrm{l}$ de una solución combinada de sustrato-buffer y se 
adicionaron $20 \mu \mathrm{l}$ de cada muestra de calostro desengrasado. En el espectrofotómetro (DYNEX MRX ${ }^{\circledR}$ a una longitud de onda de $405 \mathrm{~nm}$ ) se realizó una primera lectura que se tomó como tiempo inicial o tiempo 0 y a partir de esta medición una segunda lectura a los 60 segundos, otra a los 120 segundos y una última lectura a los 180 segundos y con los datos obtenidos se calcularon los resultados.

Con el propósito de disminuir la cantidad requerida de calostro ya que con el lactodensímetro es necesario un volumen de $250 \mathrm{ml}$, se determinó la densidad en relación peso sobre volumen mediante el picnómetro de $50 \mathrm{ml}$. Para ajustar la curva patrón de regresión del picnómetro en función del lactodensímetro, se utilizaron los valores de densidad de los 43 calostros colectados y adicionados al banco de calostro. En la determinación de densidad se utilizó el lactodensímetro marca Cole-Parmer istrumen Co (1020 - 1100 SP. G. $60 \stackrel{\circ}{\circ}$ ). Densidad ajustada 15/15: Lectura de densidad: +0.2 por ${ }^{\circ} \mathrm{C}\left(\mathrm{T}^{\circ}\right.$ del calostro es mayor a $\left.15^{\circ} \mathrm{C}\right)$. Lectura de densidad: -0.2 por ${ }^{\circ} \mathrm{C}$ (To del calostro es menor a $15^{\circ} \mathrm{C}$ ).

En la valoración de densidad con el picnómetro, se pesó el picnómetro vacío (P1), inmediatamente y teniendo el calostro a $15^{\circ} \mathrm{C}$ se colocó dentro de este, pesándolo nuevamente (P2), la densidad se calculó restando P2 de P1 y el resultado se dividió en 50 el cual es el volumen ( $\mathrm{ml}$ ) del calostro dentro del picnómetro (Figura 4).

Para el análisis de los métodos de conservación de calostro, se tomaron muestras de calostro de 4 vacas entre tres y cinco partos, que permanecieron durante el período de gestación en el predio, (que no presentaron retención de placenta, distocia, mastitis), las cuales se tomaron después de que el ternero consumiera suficiente cantidad de calostro. Lo anterior se realizó en las primeras 10 horas posparto. Las muestras se transportaron refrigeradas (dependiendo del método de conservación) al laboratorio de salud animal "La Libertad". Se evaluaron 4 métodos de conservación de calostro, a saber: almacenado a temperatura 
ambiente $\left(25^{\circ} \mathrm{C}\right)$, almacenado a temperatura ambiente $\left(25^{\circ} \mathrm{C}\right)$ con adición de ácido propiónico con una concentración final de $0.5 \%$, refrigerado $\left(8^{\circ} \mathrm{C}\right)$ y congelado $(-$ $20^{\circ} \mathrm{C}$ ). Para los tratamientos de conservación se requirió de un volumen total de $1.620 \mathrm{ml}$ por vaca.
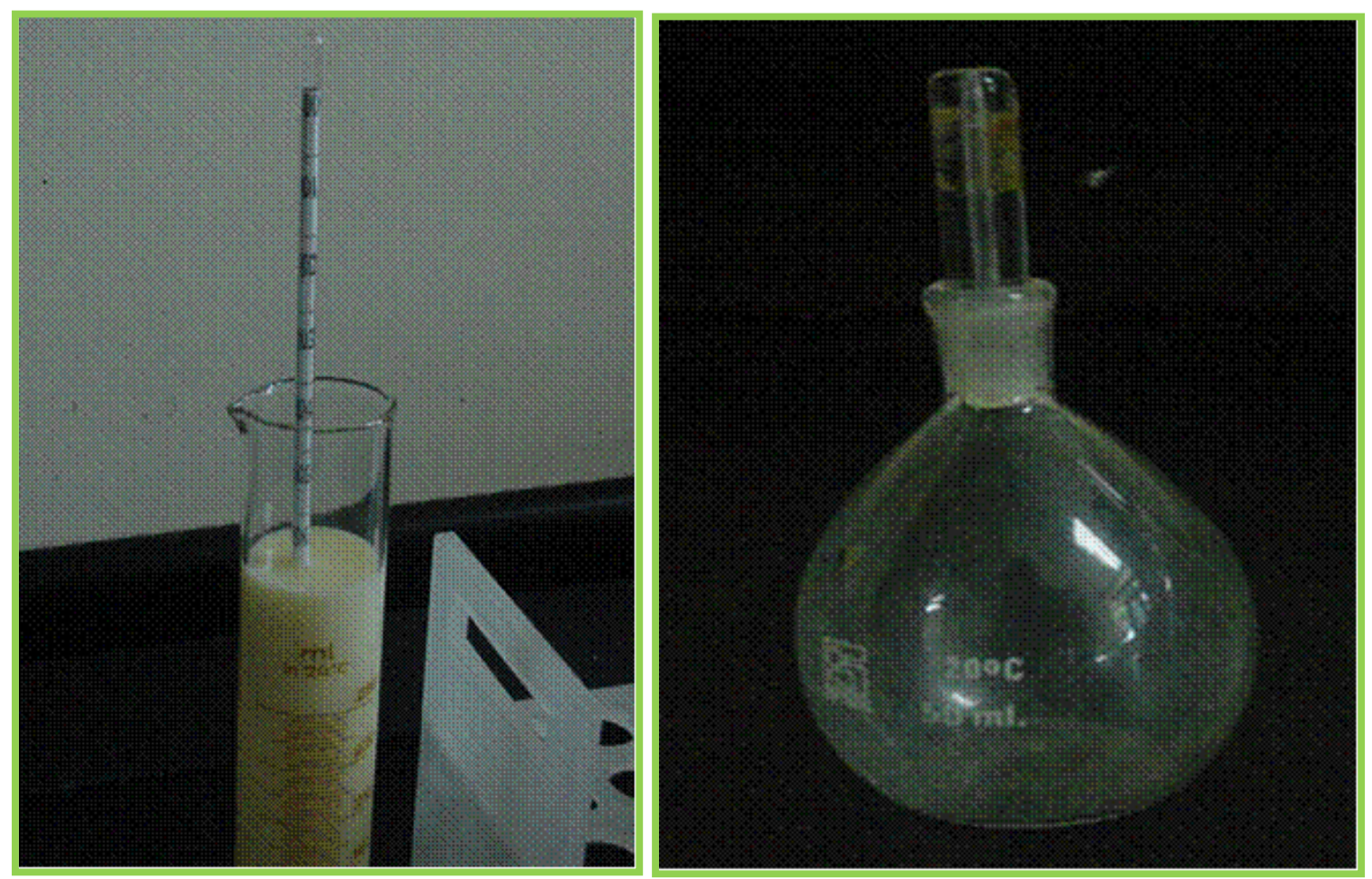

Figura 4. Picnómetro utilizado para la determinación de densidad (peso/volumen) en los calostros

Almacenado a temperatura ambiente $\left(25^{\circ} \mathrm{C}\right)$. De cada calostro se tomaron 480 $\mathrm{ml}$ que se fraccionaron en ocho alícuotas, almacenadas cada una en frascos plásticos de $60 \mathrm{ml}$, herméticamente tapados y alojados en un lugar protegido de la luz solar, a los cuales se les determino proteína, $\mathrm{pH}$, densidad y materia seca, a las 2, 3, 4, 5, 6, 8 y 10 horas a partir de la recolección.

Almacenado a temperatura ambiente $\left(25^{\circ} \mathrm{C}\right)$ con adición de ácido propiónico al $\mathbf{0 . 5 \%}$. Del calostro de cada vaca se tomaron $300 \mathrm{ml}$ a los cuales se les adicionó $1.5 \mathrm{ml}$ de ácido propiónico (concentración final 0.5\%) (Flórez, 2000), y se fraccionaron en cinco alícuotas almacenadas cada una en frascos plásticos de 60 
$\mathrm{ml}$, herméticamente tapados y alojados en un lugar protegido de la luz solar, a las cuales se les determinó proteína, pH, densidad y materia seca, a las 2, 4, 8, 12, 24 y 36 horas, a partir de la recolección.

Calostro refrigerado. De cada calostro se tomaron $480 \mathrm{ml}$, que se fraccionaron en ocho alícuotas almacenadas cada una en frascos plásticos de $60 \mathrm{ml}$, herméticamente tapados y alojados en el interior de la nevera comercial a una temperatura de $8^{\circ} \mathrm{C}$, a las cuales se les determino proteína, $\mathrm{pH}$, densidad y materia seca, a las $2,12,24,48,72,96,120,144$ y 168 horas, a partir de la recolección. Se evaluó a $8^{\circ} \mathrm{C}$ para simular la temperatura de las neveras en finca.

Calostro congelado. De cada calostro se tomaron $360 \mathrm{ml}$, que se fraccionaron en seis alícuotas de $60 \mathrm{ml}$, a las cuales se les determino proteína, $\mathrm{pH}$, densidad y materia seca a los $1,6,12,18,24$, y 30 días, a partir de la recolección. La temperatura requerida fue de $-20^{\circ} \mathrm{C}$, cada alícuota fue almacenada en frasco plástico herméticamente cerrado. El equipo utilizado para mantener esta temperatura fue un congelador comercial con formación de escarcha que mantiene las paredes cubiertas por una capa de hielo.

A cada alícuota se le midieron las siguientes variables: Proteína Cruda, se determinó por el método de MicroKjendahl, (AOAC, 2006). En la medición de la densidad, se utilizó el picnómetro, a partir de la curva patrón de regresión ajustada del picnómetro en función del lactodensímetro. pH, para esta medición se usó un potenciómetro digital (Sentron 0-14+/- 0.01), modelo PS-15. Para determinar la materia seca se pesaron $30 \mathrm{ml}$ de calostro en una balanza electrónica (Mettler PC 220 DeltaRange ${ }^{\circledR}$ Mettler Instrument AG Switzerland) utilizando una caja Petri de vidrio y se llevaron a una estufa (Gallenkamp hot box oven SG97/11/369 UK, termostato de 0 a $250^{\circ} \mathrm{C}$ ), para ser deshidratado por calor, durante 48 horas a una temperatura de $55^{\circ} \mathrm{C}$, cumplido este tiempo se peso nuevamente y se determinó el porcentaje de materia seca por medio de la siguiente fórmula: 


\section{$\% M S=\frac{P C D(g) X 100}{\text { PCND }}$}

Ms = Materia seca, $\mathrm{PCD}=$ Peso calostro desecado en gramos, $\mathrm{PCDN}=$ Peso calostro no desecado en gramos

\section{Métodos estadísticos}

Cuantificación de Ig. Curva Patrón de lg. Se realizó la curva patrón para intrapolar las concentraciones de $\lg A$, $\lg M$ e $\lg G$ con respecto al halo para el kit de $\mathrm{ICN}^{\circledR}$ para lg. Para esto se efectuaron unas regresiones donde la variable dependiente fue el diámetro del halo y la variable independiente los patrones de concentraciones de Ig para cada Kit.

Análisis de varianza. Se efectuaron unos análisis de varianza de las variables (densidad, materia seca y proteína) existentes en el banco de calostro Corpoica (72) con los valores obtenidos de los 43 calostros de las variables (densidad y materia seca) y proteína de las 25 alícuotas de calostro deshidratado, faltantes a las 72 muestras del Banco de calostro de CORPOICA.

Estadística descriptiva. Se determinó Media, Mediana, Desviación Estándar, Error estándar, Coeficiente de Variación, Mínimo, Máximo y Cuartiles, para densidad, absorbancia, pH, materia seca, cenizas, grasa, proteína, GGT, IgG, $\lg G_{1}, \lg G_{2}, \lg M, \lg A$, lg totales.

Análisis de regresión y correlación. Se hizo correlación bivariada de Pearson, para determinar el grado de asociación entre las siguientes variables: materia seca, densidad, proteína cruda, grasa, cenizas, pH, absorbancia, GGT, IgG, IgA e lgM. Cuando las variables químicas, físicas e inmunológicas, mostraron correlación significativa, se efectuó regresión lineal simple o múltiple. Se aplicó la metodología de Fleenor y Stott, (1980) quienes basaron su investigación en 29 muestras de calostro de vacas lecheras y demostraron que el contenido de lg es responsable por el $69.9 \%$ de la variación de la densidad del calostro $\left(R^{2}=0.669\right)$. 
También se aplicaron en esta investigación los estudios realizados por Quigley, 2000; Hernández y Olaya, 2004, donde indican que existen ecuaciones para predecir la calidad inmunológica del calostro basándose en la densidad, las cuales son:

$Y=254.7$ (densidad) - 261.5, midiendo la cantidad total de globulinas.

$\mathrm{Y}=1180$ (densidad) -1172 , midiendo la cantidad total de $\lg$ a $37^{\circ} \mathrm{C}$

$\mathrm{Y}=958$ (densidad) - 969 , midiendo la cantidad total de $\operatorname{lgG}$ a $20^{\circ} \mathrm{C}$

$\mathrm{Y}=39.413$ (densidad) - 34772.5 midiendo la cantidad total de $\lg$ a $15^{\circ} \mathrm{C}$

Métodos de conservación. Para cada uno de los 4 métodos de conservación se hizo un análisis estadístico de varianza independiente, utilizando un diseño al azar donde las unidades experimentales fueron los tratamientos de conservación y los tiempos de lectura.

$Y i j=\mu+T_{i}+E_{j}$

$\mu$ : Promedio General.

$\mathrm{T}_{\mathrm{i}}$ : Tiempo de Conservación del Calostro.

Ej: Error experimental.

\section{RESULTADOS Y DISCUSIÓN}

No se encontraron diferencias entre las variables densidad, materia seca y proteína, entre los valores existentes en el banco de calostro de CORPOICA y los colectados durante el estudio $(P>0.05)$, por tal motivo se utilizaron para ser correlacionadas con las variables determinadas en el presente estudio: $\lg G, \lg G_{1}$, $\lg G_{2}$, IgA, IgM, GGT y absorbancia (Tabla 2).

\section{Características físicas, químicas e inmunológicas del calostro}

La concentración media de $\mathrm{lg}$ totales fue $6.923 \mathrm{mg} / \mathrm{dL}$. Los valores promedio para cada clase de lg fueron: IgG: $5882 \mathrm{mg} / \mathrm{dL}$. $\lg \mathrm{G}_{1}: 5544 \mathrm{mg} / \mathrm{dL}$. $\lg \mathrm{G}_{2}: 338 \mathrm{mg} / \mathrm{dL}$. IgM: $670 \mathrm{mg} / \mathrm{dL} . \lg$ A: $370 \mathrm{mg} / \mathrm{dL}$. 
Tabla 2. Análisis de varianza de la proteína, densidad y materia seca en muestras de calostros deshidratados existentes en el Banco de calostro de CORPOICA

\begin{tabular}{|c|c|c|c|c|c|}
\hline Fuente de Variación & $\mathbf{g l}^{*}$ & $\begin{array}{l}\text { Cuadrado } \\
\text { Medio }\end{array}$ & $\mathbf{F}$ & Probabilidad & Promedio \\
\hline \multicolumn{6}{|l|}{ PROTEÍNA } \\
\hline Banco Calostro & 1 & 0.6756 & & & 13.2239 \\
\hline $\begin{array}{l}\text { Realizadas por los } \\
\text { autores }\end{array}$ & 55 & 6.2832 & 0.1075 & 0.7442 & 13.4433 \\
\hline Total & 56 & & & & \\
\hline \multicolumn{6}{|l|}{ DENSIDAD } \\
\hline Banco Calostro & 1 & 46.614 & & & 1057.52 \\
\hline $\begin{array}{l}\text { Realizadas por los } \\
\text { autores }\end{array}$ & 111 & 158.818 & 0.2935 & 0.589 & 1056.20 \\
\hline Total & 112 & & & & \\
\hline \multicolumn{6}{|l|}{ MATRIA SECA } \\
\hline Banco Calostro & 1 & 0.03157 & & & 20.7940 \\
\hline $\begin{array}{l}\text { Realizadas por los } \\
\text { autores }\end{array}$ & 113 & 14.1831 & 0.0022 & 0.9624 & 20.7595 \\
\hline Total & 114 & & & & \\
\hline
\end{tabular}

La densidad media fue $1.057 \mathrm{mg} / \mathrm{ml}$, materia seca $23.8 \mathrm{~g} / 100 \mathrm{~g}$ de calostro y proteína $13.3 \mathrm{~g} / 100 \mathrm{~g}$ de calostro. El promedio general para GGT y grasa fue de $730 \mathrm{UI} / \mathrm{L}$ de suero de calostro y $3.78 \mathrm{~g} / 100 \mathrm{~g}$ de calostro respectivamente. Estas dos variables presentaron los coeficientes de variación más altos. El pH medio fue 5.95 , la media para cenizas fue $1.48 \mathrm{~g} / 100 \mathrm{~g}$ de calostro y para absorbancia fue $1.07 \%$.

Existen factores importantes que influyen en el análisis de los resultados obtenidos en cuanto a propiedades físicas, químicas e inmunológicas, entre los cuales están:

1. Debido al deficiente uso de los registros en finca no se logró establecer el número de partos, ni la edad de la vaca, por consiguiente, es muy posible que estos calostros provengan de vacas con más de dos partos manifestándose en concentraciones altas de lg al ser comparadas con otros estudios. 
2. Un factor importante en la producción de calostros de buena calidad es la alimentación de las vacas durante el periodo de gestación, como es el caso de este predio en particular, el cual tiene pasturas mejoradas mediante la asociación de gramíneas y leguminosas, además ofrece suplementación a los animales, de tal forma que el nivel nutricional presente en las vacas se manifestó en la calidad del calostro.

La observación mas importante en el estudio es, que a pesar de que se utilizaron calostros de las primeras 10 horas post parto, donde se permitió amamantar al ternero y luego se colectaron, la concentración de lg fue mayor frente a otros estudios en calostro de lechería especializada de zonas templadas donde la colección de calostro se realiza inmediatamente después del parto antes del que ternero se alimente.

Son evidentes las diferencias en los valores inmunológicos y en las concentraciones de $\lg$ al igual que en las propiedades físicas y químicas que componen el calostro en vacas de ganaderías especializadas en lechería de zonas templadas que no han sido ordeñadas, en comparación con el calostro de vacas del sistema doble propósito en el trópico bajo colombiano (Piedemonte del Meta) después de dejar amamantar el ternero (Tabla 3). Esto es explicado según reportes de Wattiauxs, (2001) el cual afirma que las vacas lecheras tienen una concentración de Ig entre 6-9\%, además dentro de este sistema existen razas con menor porcentaje de $\mathrm{lg}$, como es el caso de vacas Holstein, las cuales proporcionan en su calostro una concentración menor con respecto a calostros de razas como Guernsey, Jersey, Ayrshire y Pardo Suizo. A lo anterior es de importancia referir que estas vacas (lechería especializada) por su condición lechera predisponen a volúmenes grandes de calostro y por consiguiente los sólidos totales contenidos en este se encuentran en menor cantidad debido a la dilución de los mismos. Las vacas Bos indicus presentan mayor concentración de Ig totales en calostro que las vacas Bos taurus $(P<0.05)$, porque las Ig totales 
están directamente relacionadas con el volumen de calostro producido (Parra, 2003).

Tabla 3. Comparación de medias de concentración de lg y otros componentes del calostro entre vacas lecheras de zonas templadas que no han amamantado al ternero y vacas doble propósito del trópico bajo colombiano

\begin{tabular}{ccc}
\hline Descripción & $\begin{array}{c}\text { Vacas lecheras zona } \\
\text { templada }\end{array}$ & Vacas doble propósito \\
\hline Densidad $(\mathrm{mg} / \mathrm{ml})$ & 1,056 & 1,057 \\
$\lg$ Totales $(\mathrm{mg} / \mathrm{dL})$ & 5913 & 6923,57 \\
$\lg \mathrm{G}(\mathrm{mg} / \mathrm{dL})$ & 5002 & 5882,93 \\
$\lg \mathrm{G}_{1}(\mathrm{mg} / \mathrm{dL})$ & 4690 & 5544,73 \\
$\lg \mathrm{G}_{2}(\mathrm{mg} / \mathrm{dL})$ & 3.12 & 338,2 \\
$\lg \mathrm{M}(\mathrm{mg} / \mathrm{dL})$ & 496 & 670,36 \\
$\lg \mathrm{A}(\mathrm{mg} / \mathrm{dL})$ & 415 & 370,61 \\
Sólidos totales $(\%)$ & 23,9 & 23,89 \\
Proteína Total $(\%)$ & 14 & 13,32 \\
Grasa $(\%)$ & 6,7 & 3,78 \\
Minerales $(\%)$ & 1,11 & 1,48 \\
\hline
\end{tabular}

Respecto a la densidad, la ecuación obtenida en la curva de regresión lineal (Figura 5), para la determinación de densidad; utilizando el picnómetro en función del lactodensímetro fue la siguiente: $Y_{i}=0.9498 x_{i}+53.826$ donde: $y_{i}:$ Valor densidad observada con picnómetro, $\mathrm{x}_{\mathrm{i}}$ : Variación en la densidad del lactodensímetro y $\mathrm{R}^{2}=0.9572$.

Al realizar un análisis de varianza entre los valores obtenidos con el picnómetro en el laboratorio y los valores calculados por la ecuación presentó una probabilidad de 0.77 , lo cual indica que es necesario ajustar aún más el uso del picnómetro en función del lactodensímetro. El anterior resultado proporciona un acercamiento hacia la utilidad que ofrece el picnómetro, con lo cual se espera que con la realización de posteriores investigaciones en base a este aspecto se disponga de una alternativa confiable, con la cual se requeriría de un volumen de muestra de 
calostro menor, con esto la labor de transporte, almacenamiento y consecución de las muestras se convertiría en una labor más práctica.

Los datos obtenidos de densidad en calostro del sistema doble propósito estuvieron entre $1033.5 \mathrm{mg} / \mathrm{dL}$ y $1089.0 \mathrm{mg} / \mathrm{dL}$, el amplio rango de densidad esta dado porque las muestras provienen de vacas de diferente número de parto, así como el hecho que los calostros fueron colectados a diversas horas posparto en las primeras 10 horas. La media de densidad fue $1057 \mathrm{mg} / \mathrm{dL}$. El histograma presenta tres grupos definidos de densidad; el primer grupo está conformado por las densidades de $1033.5-1050.17 \mathrm{mg} / \mathrm{ml}$; el segundo entre $1050.8-1061.29 \mathrm{mg} / \mathrm{ml}$ y el tercero entre 1061.3-1089.09 mg/ml (Figura 6).

Según Flórez, (2000) calostros con densidades inferiores a $1050 \mathrm{mg} / \mathrm{ml}$ son de baja calidad por su bajo contenido de $\mathrm{lg}$, porque ofrecen menos de $50 \mathrm{mg} / \mathrm{ml}$ de $\mathrm{lg}$ totales en calostro. En el presente estudio, calostros con una densidad de 1042 $\mathrm{mg} / \mathrm{ml}$ (media para el primer grupo en el histograma) contienen $62.79 \mathrm{mg} / \mathrm{ml}$ de $\mathrm{lg}$ totales, concentración suficiente para proporcionar un nivel sérico de lg totales aproximadamente de $9.5 \mathrm{mg} / \mathrm{ml}$ en las primeras dos horas de vida. A partir de este criterio, la diferencia entre los tres grupos radica en la cantidad de volumen necesaria para ofrecer una adecuada protección inmune al ternero.

$\mathrm{El} \mathrm{pH}$ promedio obtenido fue 5.95, los datos se encuentran distribuidos entre los rangos de 4.77 y 6.51 ; el $81 \%$ de las muestras se ubicaron entre 5.89 y 6.61 , correspondiendo en la gráfica a una distribución con tendencia a la derecha (Figura 7). Respecto a la absorbancia los calostros presentaron una alta variabilidad o dispersión de los valores, el promedio obtenido fue de 1.07\% medido en espectrofotómetro a una longitud de onda de $630 \mathrm{~nm}$. (Figura 8).

El promedio de materia seca fue $23.89 \mathrm{~g} / 100 \mathrm{~g}$ de calostro. De forma similar que el histograma de densidad; materia seca forma 3 grupos definidos: Grupo 1 (13.30$21.21 \%$ de sólidos totales) representado en el $22.61 \%$ de las muestras, Grupo 2 (21.22-27.15\%) con el $59.13 \%$ de las muestras y el Grupo 3 (27.17-33.09\%) 
ocupado por el $18.26 \%$ de los calostros. Al comparar los histogramas de densidad y materia seca se observó una relación directa la cual es explicada por la conformación de los tres grupos en el histograma. El 59.13\% de las muestras se ubicaron en el grupo dos; la diferencia entre los tres grupos, a pesar de presentar un buen porcentaje de sólidos totales, es el mayor o menor contenido de sus componentes explicados por el número de parto de las vacas (Figura 9).
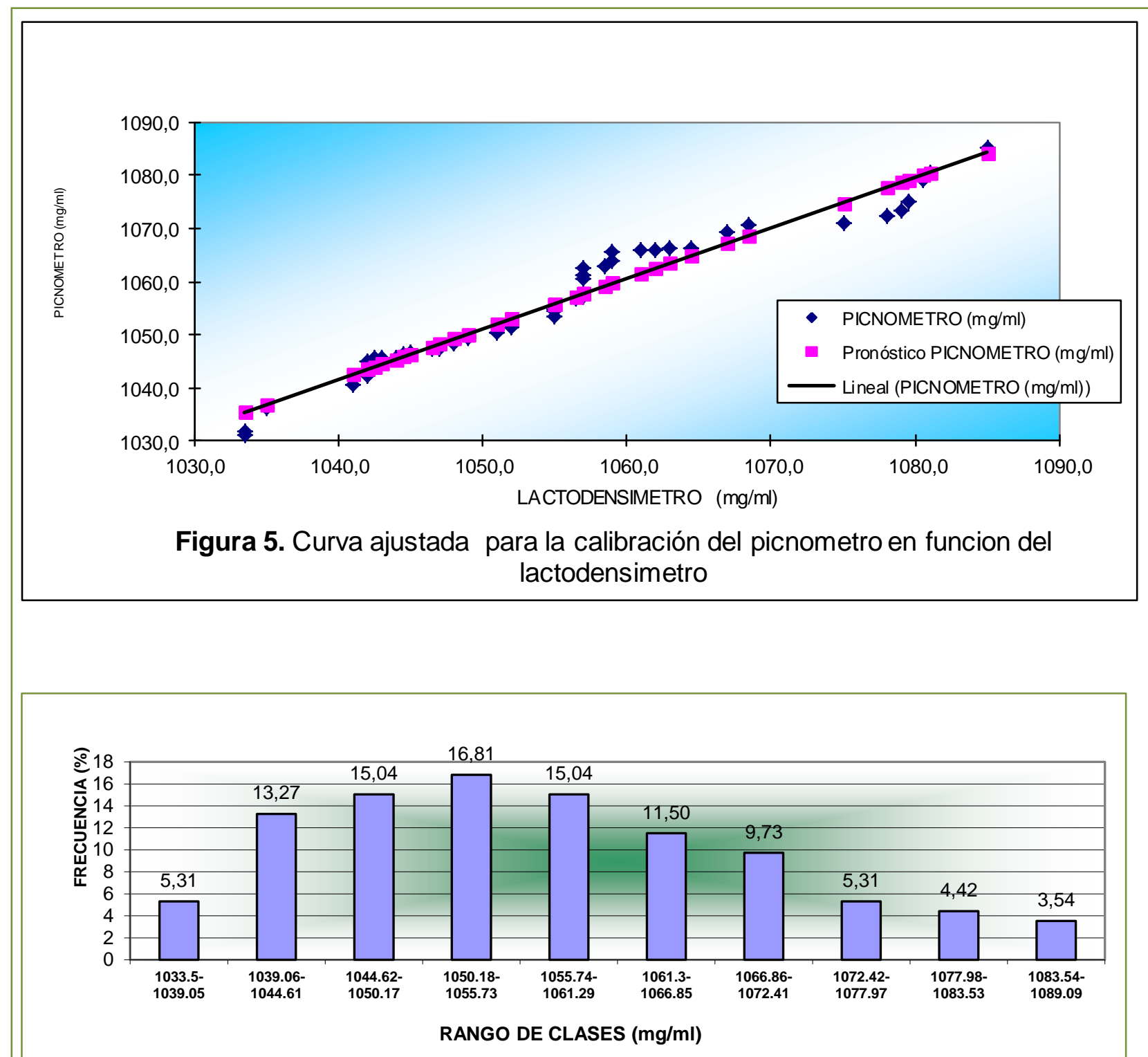

Figura 6. Frecuencia densidad ( $\mathrm{mg} / \mathrm{ml}$ de calostro) 


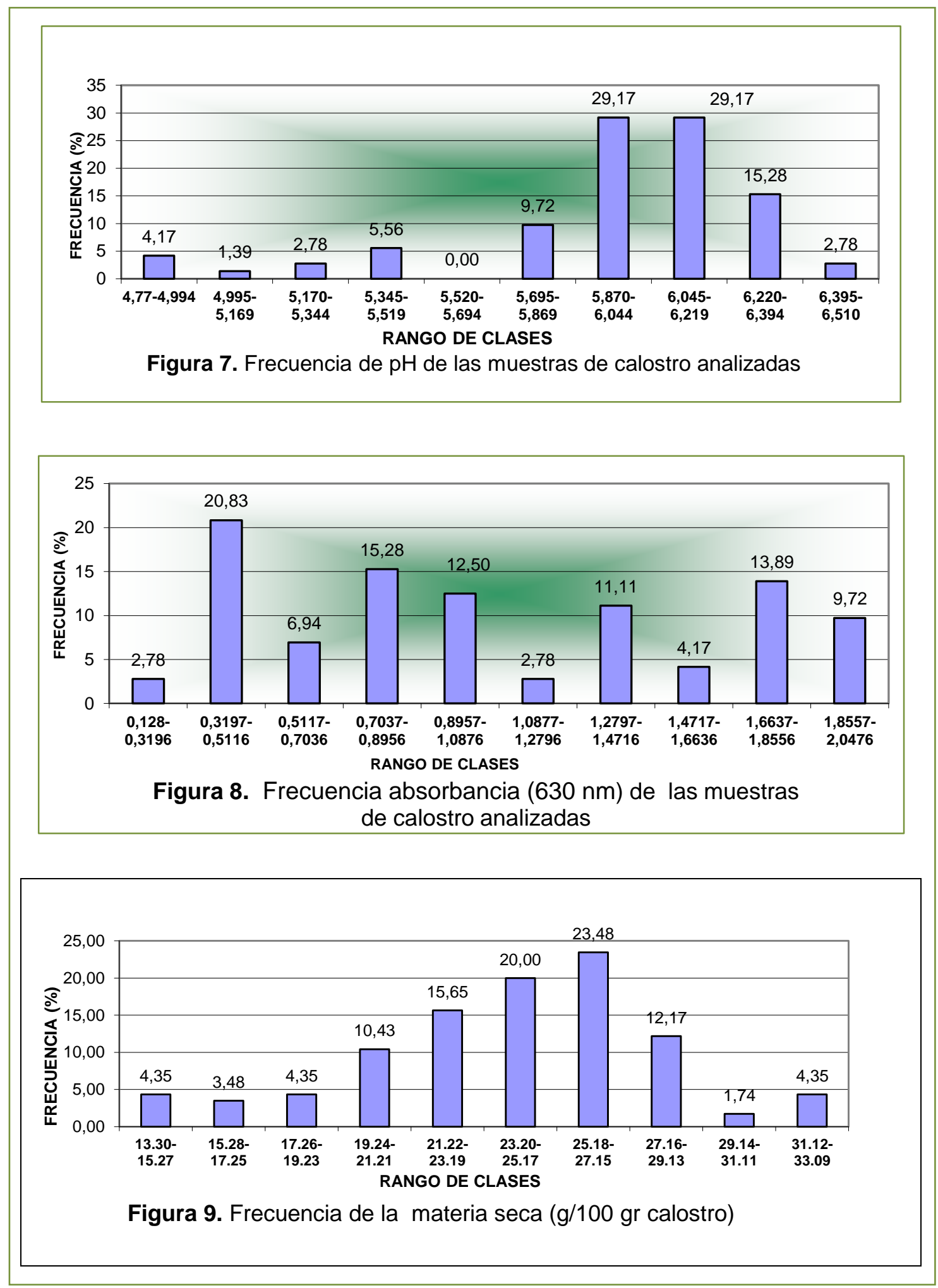


El valor medio de cenizas se encontró en $1.48 \mathrm{~g} / 100 \mathrm{~g}$ de calostro, el $75 \%$ de las muestras se encontró entre $0.77-1.40 \mathrm{~g} / 100 \mathrm{~g}$ de cenizas formando en la gráfica una distribución con tendencia a la izquierda (Figura 10).

El valor medio de grasa fue de $3.77 \mathrm{~g} / 100 \mathrm{~g}$ de calostro, este es inferior al publicado por Flórez, (2000) de 6.7 g/100 g en vacas de lechería especializada de zonas templadas; lo anterior es explicado por las diferencias en la alimentación y la variabilidad genética; sin embargo se presentó un $20.5 \%$ de muestras que superaron el valor citado por este autor, lo cual indica que aunque las condiciones de producción y sanidad no son las mismas para los dos sistemas, en comparación sobresale la calidad del calostro en el sistema doble propósito (Figura 11).

En la proteína cruda persiste la formación definida de grupos, el $10.53 \%$ de las muestras están entre $8.53-10.58 \mathrm{~g} / 100 \mathrm{~g}$ de calostro; el $52.63 \%$ de las muestras están entre rangos de 10.59-13.67 g/100 g de calostro y el $36.84 \%$ tiene los valores de 13.68-19.82 g/100 g de calostro. Este último grupo supera el valor publicado por Flórez, (2000) donde el porcentaje de proteína en vacas de lechería especializada en zonas templadas es de $14 \mathrm{~g} / 100 \mathrm{~g}$; lo anterior confirma la calidad del calostro en el sistema doble propósito. El valor promedio de proteína fue de $13.32 \mathrm{~g} / 100 \mathrm{~g}$ de calostro (Figura 12).

En cuanto a gamma glutamil transferasa (GGT) el $60 \%$ de las muestras presentaron niveles entre 0.00 y $461.6 \mathrm{UI} / \mathrm{L}$ de calostro. El valor medio fue 730.86 UI/L. Los niveles de GGT pueden alcanzar hasta 200 veces más el contenido de esta enzima en suero sanguíneo; se estaría entonces hablando de niveles mínimos superiores a $3000 \mathrm{UI} / \mathrm{L}$ de calostro. En este caso solamente el $4.17 \%$ de las muestras superan este valor (Figura 13). 


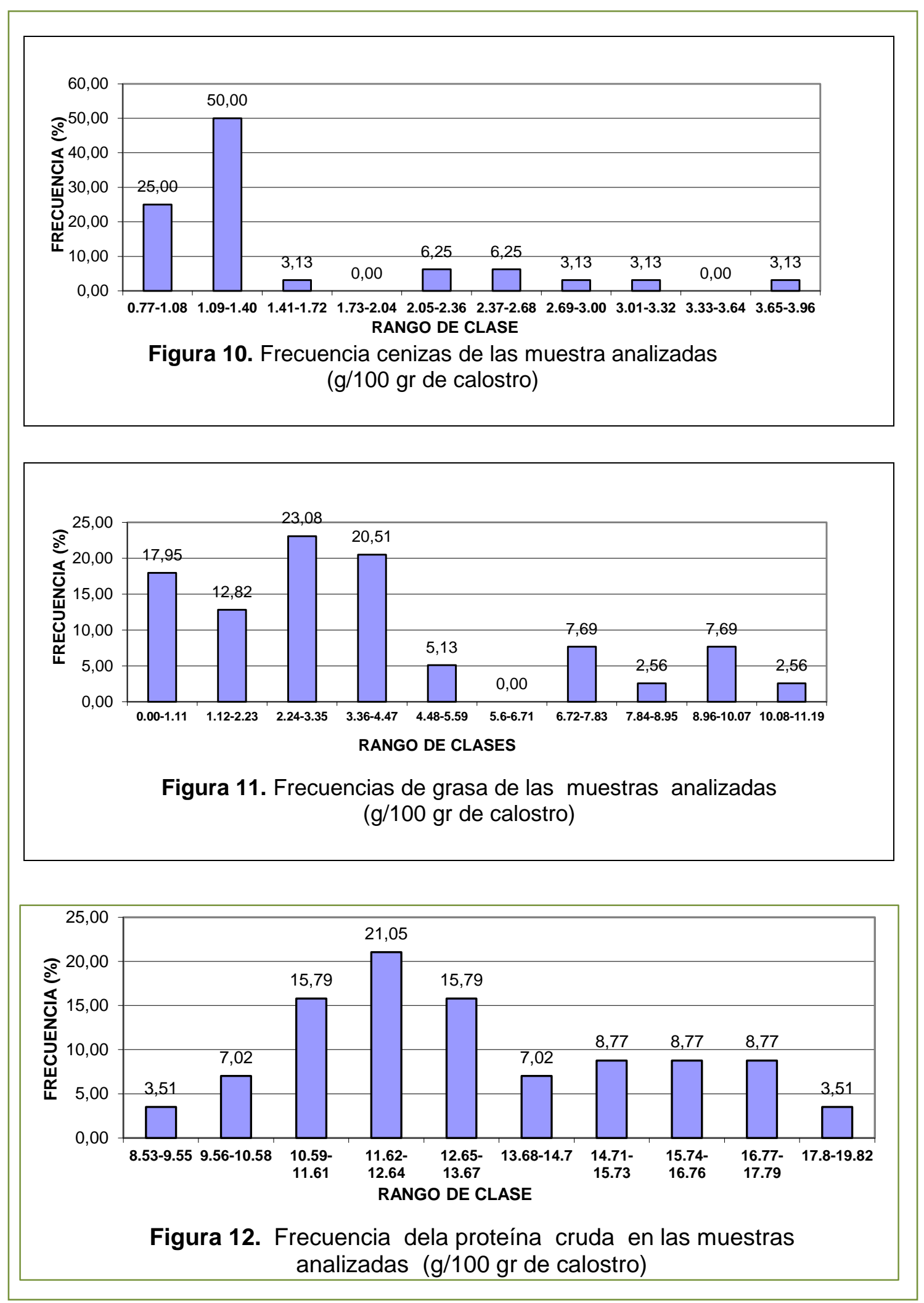




\section{Características inmunológicas}

El valor medio de IgG obtenido fue $5862.93 \mathrm{mg} / \mathrm{dL}$; el $84.7 \%$ de las muestras resultaron con niveles superiores a los reportados en la literatura (por kit Biomedicals ICN, 2003) en ganadería especializada de lechería en zonas templadas $(5050 \mathrm{mg} / \mathrm{dL})$. El histograma presentó la formación de tres grupos; indicando la relación directa de $\lg G$ entre densidad, materia seca representada por la concentración de $\lg G$ en cada uno de los grupos del histograma. El primer grupo se encuentra entre los valores de (3608.2-5537.96 mg/dL), correspondiendo al $25 \%$ del total de las muestras, el segundo de $(5537.97-6695.81 \mathrm{mg} / \mathrm{dL})$, representando el $66.6 \%$, el tercer grupo $(6695.82-7467.72 \mathrm{mg} / \mathrm{dL})$ con el $8.33 \%$ (Figura 14).

Respecto a los subtipos de $\lg G$ ( $\lg G_{1}$ e $\left.\lg G_{2}\right)$, consecuente con la formación de grupos en el histograma de lgG, estos comparten su distribución porcentual en el histograma. El $28.3 \%$ de las muestras obtenidas para lgG $\mathrm{I}_{1}$ están entre los rangos de 5583 - $6947 \mathrm{mg} / \mathrm{dL}$, valor superior al dado por la referencia. El valor medio fue de $5544.73 \mathrm{mg} / \mathrm{dL}$. En cuanto a la lgG el valor medio fue 338.2 , el $49 \%$ están entre los rangos de 318 - $382 \mathrm{mg} / \mathrm{dL}$ (Figuras 15 y 16).

En la lgM la media obtenida fue $670 \mathrm{mg} / \mathrm{dL}$, valor superior al compararlo con niveles reportados por Vann et al., (1995) ICN Biomedicals ${ }^{\circledR}$, (2003) de 390 mg/dL y $420 \mathrm{mg} / \mathrm{dL}$ respectivamente. El histograma presentó tres grupos definidos de concentraciones de IgM. El $77.8 \%$ de los calostros mostraron un valor superior e inclusive tres veces mayores con respecto al valor reportado en la literatura; el $22.22 \%$ de las muestras se ubican en los rangos de $491-612 \mathrm{mg} / \mathrm{dL}$ y el $11 \%$ fueron inferiores a los reportados por la literatura: 7.44-370.60 mg/dL (Figura 17).

El valor medio de IgA para el estudio fue de $370.6 \mathrm{mg} / \mathrm{dL}$; se destaca el porcentaje de muestras entre los rangos $401.9-468.2 \mathrm{mg} / \mathrm{dL}$ (13\%) y $468.2-534.6 \mathrm{mg} / \mathrm{dL}$ (21.9\%). Se presentaron niveles mayores a $600 \mathrm{mg} / \mathrm{dL}$ de calostro en un $2.74 \%$ del total de las muestras (Figura 18). 


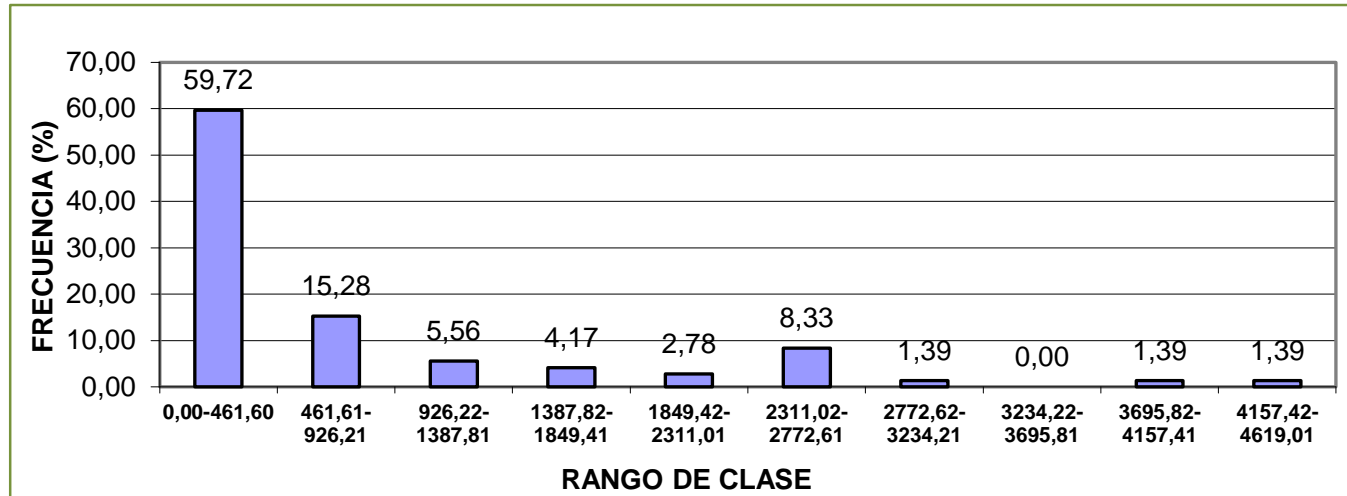

Figura 13. Frecuencia de las concentraciones de GGT en las muestras analizadas (U/L suero de calostro)

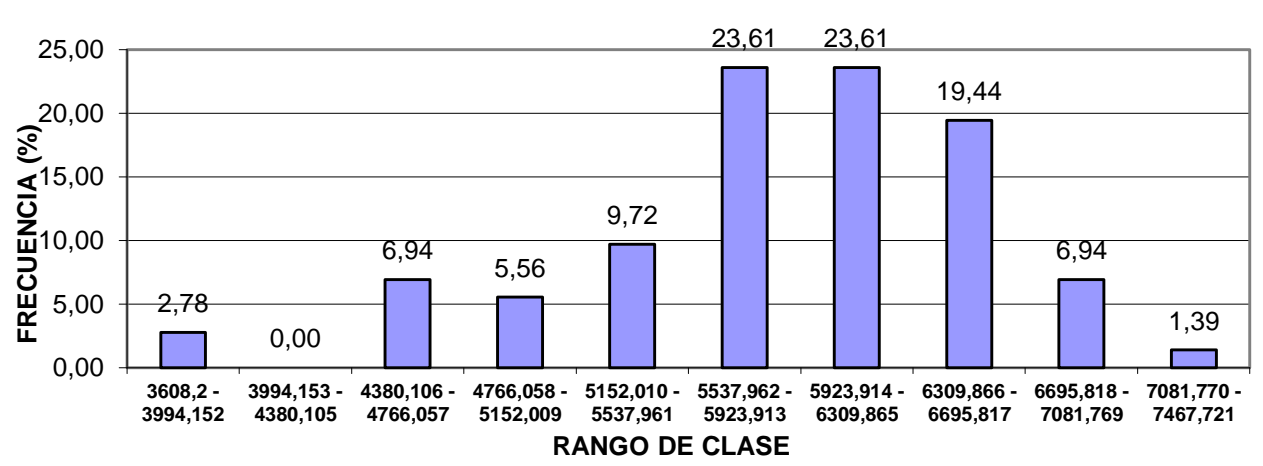

Figura 14. Frecuencias de $\lg \mathrm{G}$ de las muestras de calostro (mg/dL)

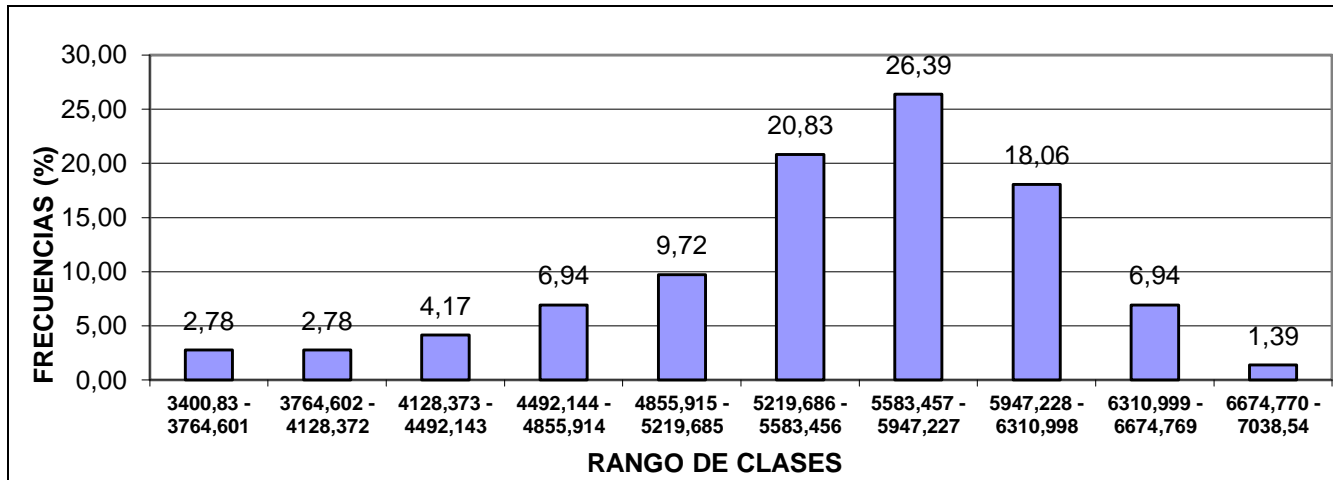

Figura 15. Frecuencia de la concentración de lg G1 en el calostro $(\mathrm{mg} / \mathrm{dL})$ 

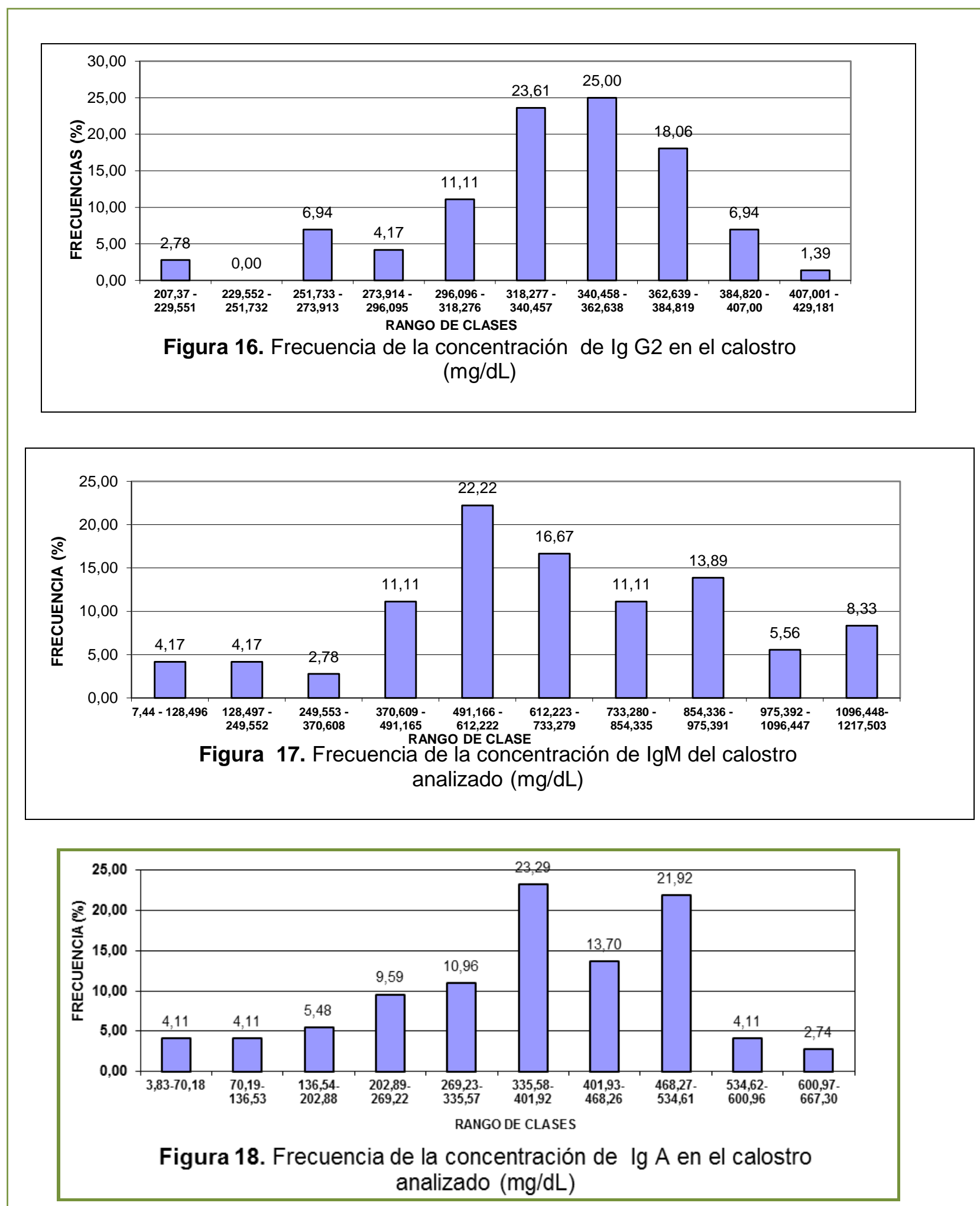
El valor medio de $\mathrm{lg}$ totales fue $6923.57 \mathrm{mg} / \mathrm{dL}$, el cual es superior al promedio encontrado en reportes ICN Biomedicals ${ }^{\circledR}$, (2003) Flórez, (2000) y Parra, (2003) 5780,5860 y $4800 \mathrm{mg} / \mathrm{dL}$ respectivamente en ganado de lechería especializada en zonas templadas, e inferiores a los reportados por Barrington et al., (2001) en vacas Holstein y Pardo Suizo en zonas templadas antes de ser amamantado el ternero (8100 mg/dL) y después de ser amamantado (5800 mg/dL) (Figura 19).

Los anteriores estudios se aproximan al apreciable valor inmunológico aportado por vacas del sistema doble propósito; ya que, aunque los valores reportados por el presente estudio se encuentran entre los valores internacionales, la gran diferencia radica en que son calostros evaluados después de que el ternero lo ha consumido.

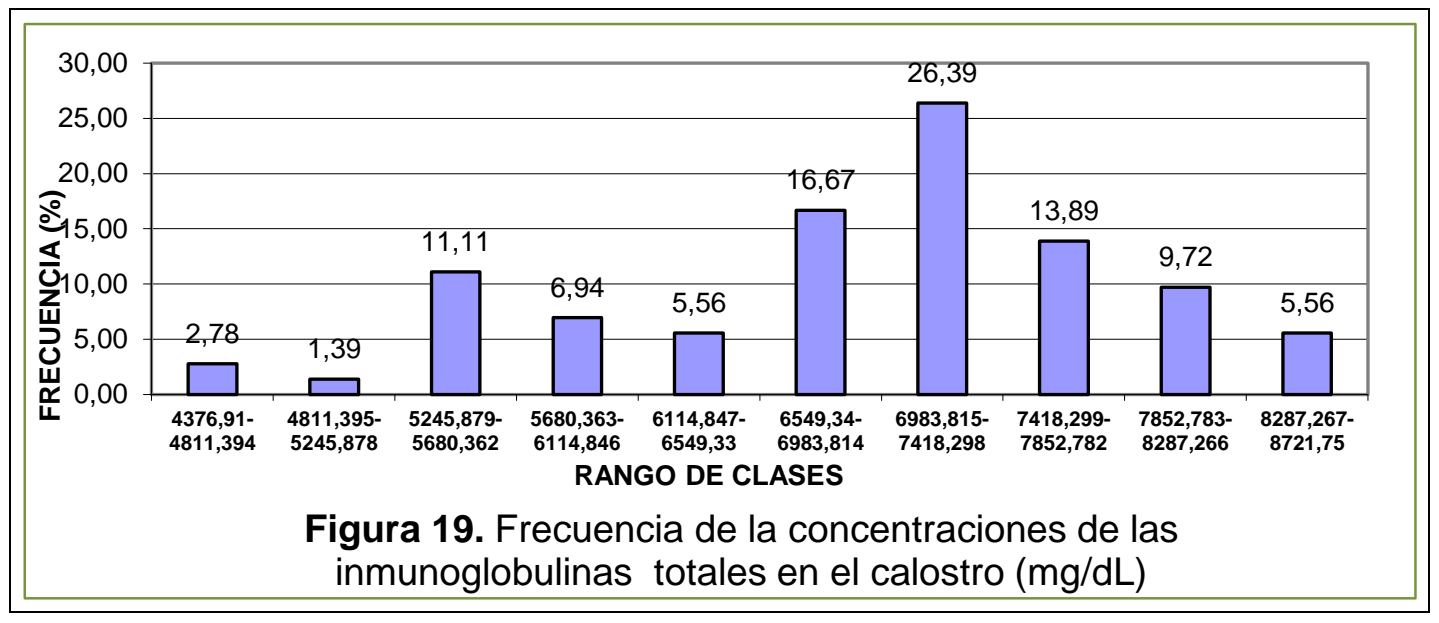

Corroborando la calidad inmunológica de los calostros en evaluación, reportada por Flórez en el 2000, el cual dice que calostros que contengan una concentración mayor o igual a $50 \mathrm{mg} / \mathrm{ml}$ de $\mathrm{lg}$ en calostro son de excelente calidad debido a su aporte inmunológico, el $95.84 \%$ de los calostros colectados para el presente estudio contienen una concentración mayor o igual a 50 mg/dL (Figura 19).

Las curvas patrón de regresión ajustadas del diámetro del halo en función de las concentraciones de las diferentes Ig $A, G_{2}$ y $M$ se presentan en la Figura 20, con su respectiva ecuación. Se observa una correlación directa entre la concentración 
de la lg con el diámetro de halo, siendo la de mayor el halo de la $\lg \mathrm{G}_{2}$ (11 mm) a una concentración de $130 \mathrm{mg} / \mathrm{dL}$ en comparación con las otras dos, en donde el halo de la $\lg \mathrm{M}(11 \mathrm{~mm})$ con una concentración de $550 \mathrm{mg} / \mathrm{dL}$ y en $\operatorname{la} \lg \mathrm{A}$, su halo no pasa de $10 \mathrm{~mm}$ a una concentración de $410 \mathrm{mg} / \mathrm{dL}$.
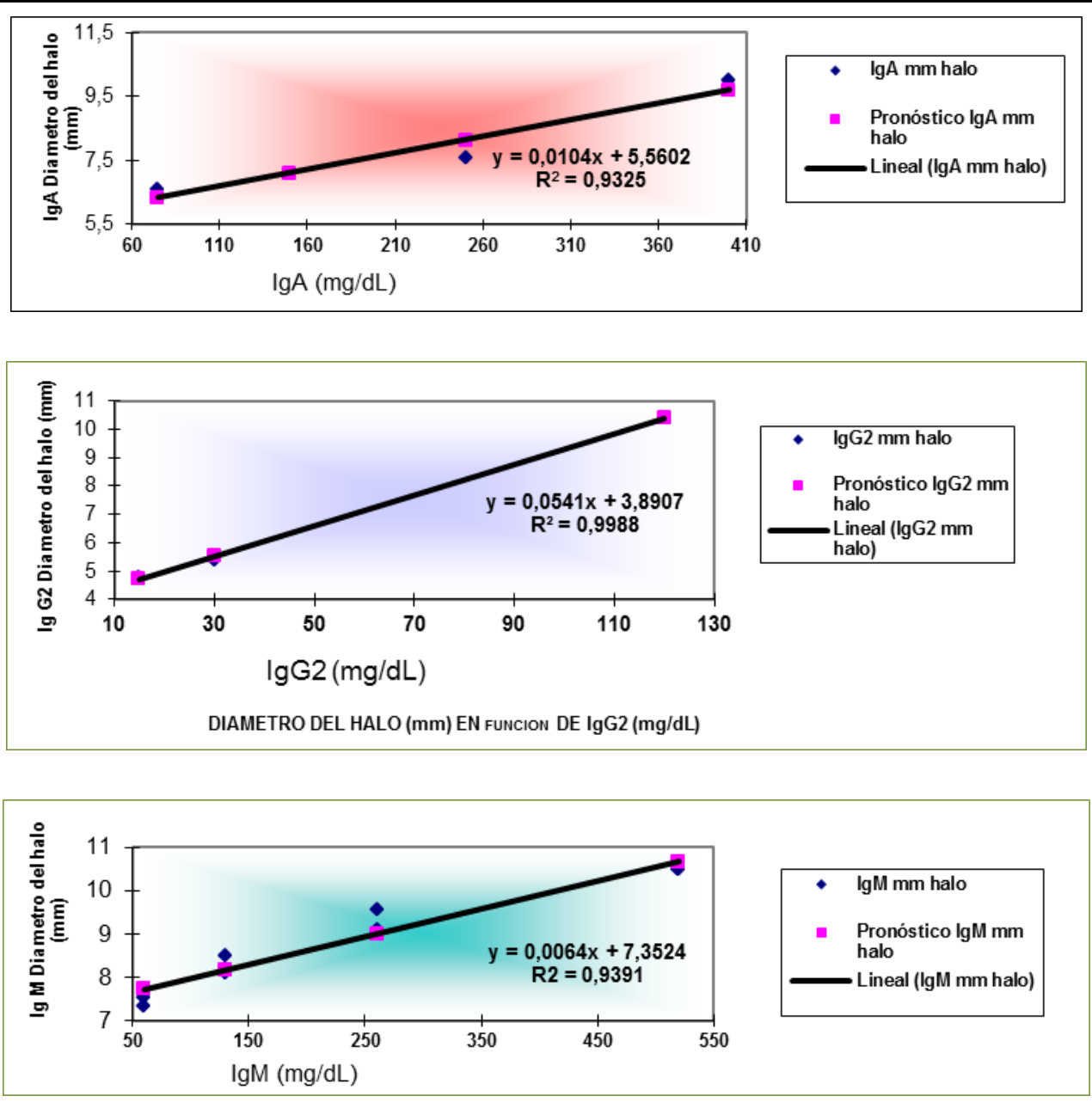

Figura 20. Diámetro del halo ajustado en función de las concentraciones de inmunoglobulinas A, G2 y M.

Varios estudios reportan la ecuación obtenida para determinar concentración de globulinas en función de densidad, observándose en el presente estudio la aproximación de la relación de las Ig con densidad, teniendo en cuenta que está influenciada por factores externos como manejo de la prueba, método utilizado 
para desengrasar las muestras, temperatura a la cual fueron almacenadas, entre otras; por lo tanto es necesario continuar con la investigación exhaustiva y completa controlando aún más las variables que afectan la interpretación de los resultados. La ecuación obtenida se basó en los estudios de Fleenor y Stott, (1980) para la determinación de Ig en función de densidad que fue la siguiente: $y_{i}$ = $-34772.5\left(x_{j}\right)+39.413$ donde: $y_{i}=$ Variación en la concentración de $\lg (\mathrm{mg} / \mathrm{dL}) ; x_{j}=$ Valor de densidad observado $(\mathrm{mg} / \mathrm{ml})$ y $R^{2}=0.230$

Al obtener un coeficiente de determinación de 0.23 indica que la concentración de Ig es responsable del $23 \%$ de la variación de la densidad; la variación entre las ecuaciones reportadas en la literatura por Quigley, 2000; Hernández y Olaya, 2004 y la obtenida por los autores se debe a la diversificación de metodología y obtención de las muestras. Además, se evaluó un modelo de regresión lineal múltiple para determinar lg a partir de densidad y materia seca obteniendo la ecuación: $y_{i}=-38261.5+43.324\left(x_{1}\right)-25.387\left(x_{2}\right)$ donde: $y_{i}=$ Variación en la concentración de lg; $x_{1}=$ Valor de densidad observado $(\mathrm{mg} / \mathrm{ml}) ; x_{2}=$ Valor de materia seca observado ( $g / 100 \mathrm{~g}$ calostro) y $R^{2}=0.222$

El modelo obtenido para la determinación de lg a partir de una regresión lineal múltiple entre densidad y materia seca demostró un modelo de ecuación, la cual tiene un $R^{2}=0.222$. Lo anterior conlleva a la necesidad de continuar en la investigación de la interacción de las variables en estudio, con el fin de ajustar un modelo de determinación más preciso, como herramienta útil en laboratorio. Las IgG e IgA mostraron una correlación positiva, y la ecuación para determinar IgG a partir de IgA es la siguiente: $y_{i}=4440.838+3.808\left(x_{j}\right)$ donde: $y_{i}$ : Variación en la concentración de $\lg G(\mathrm{mg} / \mathrm{dL}) ; x_{j}$ : Valor de $\lg A$ observado $(\mathrm{mg} / \mathrm{dL})$ y $\mathrm{R}^{2}: 0.379$

Para el caso contrario, es decir, predecir la concentración de IgA a partir de la concentración de IgG la ecuación es: $y_{i}=-249.645+0.105\left(x_{i}\right)$ donde: $y_{i}$ : Variación en la concentración de IgA (mg/dL); $x_{i}$ : Valor concentración de lgG observado $(\mathrm{mg} / \mathrm{dL})$ y $R^{2}: 0.379$. 
Para determinar la concentración de $\lg G$ en función de $\lg A$, densidad y absorbancia la ecuación lineal múltiple obtenida fue la siguiente: $y_{i}=-22315.6+$ $3.860\left(x_{1}\right)+24.857\left(x_{2}\right)+517.044\left(x_{3}\right)$ donde: $y_{i}$ : Variación en la concentración de $\lg G$ (mg/dL); $x_{1}$ : Valor co; $x_{3}$ : Valor de absorbancia observado (\%) y $R^{2}=0.543$.

La interacción de más de una variable proporciona un modelo más ajustado. La mayor dificultad que presenta la determinación de $\lg G$ a partir de $\lg A$ y absorbancia es el costo incurrido en la prueba ya que es necesario contar con el kit y un espectrofotómetro. Por otro lado, la proteína cruda presentó tres ecuaciones simples correlacionadas positivamente y explicadas con base a materia seca, densidad y cenizas, las cuales se presentan a continuación:

Proteína en función de Materia Seca: $y_{i}=-0.942+0.558\left(x_{i}\right)$ donde: $y_{i}:$ Variación en la concentración de proteína ( $g / 100 \mathrm{~g}$ calostro); $x_{i}$ : Valor de materia seca observado (g/100g calostro) y $R^{2}: 0.354$.

Proteína en función de densidad: $y_{i}=-120.700+0.127\left(x_{i}\right)$ donde: $y_{i}$ : Variación en la concentración de proteína (g/100 g calostro); $x_{i}$ : Valor de densidad observado $(\mathrm{mg} / \mathrm{ml})$ y $R^{2}: 0.371$.

Proteína en función de Cenizas: $y_{i}=10.543+1.708\left(x_{i}\right)$ donde: $y_{i}$ : Variación en la concentración de proteína en calostro ( $g / 100 \mathrm{~g}$ calostro); $x_{i}$ : Valor de Cenizas observado (g/100 g calostro) y $R^{2}: 0.228$.

Densidad en función de Materia Seca: $y_{i}=1010.061+1.965\left(x_{i}\right)$ donde: $y_{i}$ : Variación en la densidad del calostro $(\mathrm{mg} / \mathrm{ml}) ; x_{i}$ : Valor de la materia seca observada $(\mathrm{g} / 100 \mathrm{~g}$ calostro) y $R^{2}: 0.41$.

De los modelos de ecuación resultantes entre las variables de mayor correlación explican en un valor inferior al 50 \% la variación entre ellas; por tal razón es aún prematuro determinar la calidad del calostro por variables diferentes a la cuantificación de lg. 
Se observaron diferentes tipos de calostro de acuerdo a la densidad porque los promedios de la estadística descriptiva de las variables evaluadas y los cuartiles de densidad fueron diferentes $(\mathrm{P}<0.05)$ en los cuartiles por densidad para cenizas, proteína cruda, materia seca, lg total, lgG, lgG1, lgG2 y GGT; no así, para grasa, $\mathrm{pH}$, IgA, IgM y absorbancia $(P>0.05)$ (Tabla 4), por lo tanto los calostros se clasificaron en cuatro grupos (cuartiles) ordenados de menor a mayor a partir de los valores de densidad así:

Tabla 4. Grupos de calostro con base a densidad de dos predios del sistema doble propósito del Piedemonte del Meta.

\begin{tabular}{|c|c|c|c|c|}
\hline \multirow{2}{*}{ Variables } & \multicolumn{4}{|c|}{ Calostro } \\
\hline & Tipo 1 & Tipo 2 & Tipo 3 & Tipo 3 \\
\hline Densidad $\left(\mathrm{mg} / \mathrm{ml}\right.$ a $\left.15^{\circ} \mathrm{C}\right)$ & 1042 & 1054.13 & 1067.31 & 1081.9 \\
\hline Cenizas (g/100 g calostro) & 1.15 & 1.23 & 2.08 & 2.38 \\
\hline Grasa (g/100 g de calostro) & 5.19 & 3.84 & 2.62 & 4.01 \\
\hline Proteína (g/100 g calostro) & 11.64 & 12.69 & 14.46 & 17.62 \\
\hline Materia Seca (g/100 g calostro) & 20.66 & 23.17 & 26.05 & 29.98 \\
\hline $\mathrm{pH}$ & 5.974 & 5.91 & 5.96 & 6.08 \\
\hline $\lg A(\mathrm{mg} / \mathrm{dl})$ & 354.47 & 352.04 & 394.5 & 418.49 \\
\hline $\lg \mathrm{G}(\mathrm{mg} / \mathrm{dl})$ & 5377.14 & 5859.89 & 6155.85 & 6245.87 \\
\hline $\lg \mathrm{G}_{1}(\mathrm{mg} / \mathrm{dl})$ & 5068.11 & 5522.86 & 5798.3 & 5886.55 \\
\hline $\lg \mathrm{G}_{2}(\mathrm{mg} / \mathrm{dl})$ & 309.03 & 337.03 & 353.55 & 358.94 \\
\hline $\lg M(\mathrm{mg} / \mathrm{dl})$ & 547.72 & 667.19 & 728.19 & 745.35 \\
\hline Total lg (mg/dl) & 6279.32 & 6879.12 & 7254.55 & 7409.32 \\
\hline GGT (UI/L) & 623.04 & 406.67 & 807.49 & 2681.74 \\
\hline
\end{tabular}

Cuartil 1 ó calostro tipo 1: 1033.5-1047 mg/ml: para utilizar como suplemento nutricional en los terneros neonatos principalmente a partir de las 24 horas de nacido. En casos especiales puede emplearse para proveer inmunidad pasiva procurando que el ternero ingiera mínimo 2.9 litros de calostro con estas características en las primeras tres horas de vida

Cuartil 2 ó calostro tipo 2: 1047.5-1061 mg/ml: Se le puede dar el mismo uso que los calostros de cuartil uno, sin embargo, de no disponer de un calostro de mayor 
densidad, asegurarse de que el ternero consuma una cantidad mínima de 2.6 litros de este calostro en las primeras 3 horas de nacido.

Cuartil 3 ó calostro tipo 3: 1061.5-1075 mg/ml: Por su valor inmunológico se recomienda utilizarlo para transferir una adecuada inmunidad al ternero recién nacido. Suministrar al ternero mínimo una cantidad de 2.5 litros de este calostro en las primeras 2 horas de vida y el excedente de calostro almacenarlo para otros terneros posteriormente

Cuartil 4 ó calostro tipo 4: 1075.5-1089 mg/ml: es un calostro ideal para garantizar una excelente inmunidad al ternero. Procurar que el ternero recién nacido ingiera mínimo 2 litros de este calostro en las 2.4 primeras horas de nacido. El calostro excedente almacenarlo para los terneros que nacerán posteriormente.

\section{MÉTODOS DE CONSERVACIÓN DE CALOSTRO}

No se presentaron diferencias en los tiempos de medición para cada uno de los tratamientos de conservación $(P<0.05)$, el no cambio de las variables medidas puede ser atribuido a que el calostro por su mayor contenido de sustancias bacteriostáticas (lactoferrina) y bactericidas (lizosimas, opsoninas, células blancas) comparado con los niveles presentes en la leche, logra preservarse por más tiempo al inhibir el crecimiento bacteriano y micótico.

Para lograr un buen almacenamiento es importante realizar una adecuada colección del calostro bajo condiciones higiénicas, de esta forma mantiene por más tiempo las características propias del mismo. El método a elegir sin duda alguna es el congelado, pero no es posible aplicarlo en la totalidad de los predios; por tal razón es importante tener en cuenta los resultados obtenidos en el presente estudio con los demás tratamientos evaluados.

Método de conservación a temperatura ambiente $\left(25^{\circ} \mathrm{C}\right)$. La estadística descriptiva de densidad, proteína, materia seca y $\mathrm{pH}$, evaluadas con este método de conservación durante las 10 horas de almacenamiento, no presentó diferencias 
significativas. El éxito de la conservación es mantenerlo protegido de los rayos solares, recolectarlo en recipientes limpios y herméticamente cerrados. Los calostros presentaron una temperatura interna de $24^{\circ} \mathrm{C}$ a las 2 horas de almacenamiento, oscilando la temperatura durante la hora 4-6 un grado por encima de la primera lectura y a la hora 10 de evaluación fue de $25^{\circ} \mathrm{C}$. El no cambio de las variables evaluadas durante 10 horas de almacenamiento puede ser explicado a que la temperatura ambiente $\left(25^{\circ} \mathrm{C}\right)$ es un rango límite para controlar el crecimiento progresivo de levaduras, hongos y bacterias (Parra, 2003).

Método de conservación almacenados a temperatura ambiente $\left(25^{\circ} \mathrm{C}\right)$ con la adición de ácido propiónico al $\mathbf{0 . 5 \%}$. El comportamiento de la temperatura interna de los calostros en la primera evaluación (2 horas) fue de $24^{\circ} \mathrm{C}$, y entre la hora 4 y 6 la temperatura disminuyo $3^{\circ} \mathrm{C}$ gradualmente, para terminar en $21^{\circ} \mathrm{C}$ a las 36 horas de almacenamiento.

En el momento de adicionar el ácido propiónico al calostro se debe tener ciertas consideraciones, entre las que están: colocar la concentración adecuada para evitar sobredosificación del uso del ácido propiónico para evitar sobre dosificación, además en el momento de adicionarlo el calostro debe ser agitado proporcionando completa homogenización de los dos líquidos para evitar la formación de coágulos, durante el tiempo de almacenamiento se debe agitar constantemente para evitar la estratificación de los sólidos totales. El olor que tiene el ácido es fuerte, lo cual podría ser una desventaja al momento de ser suministrado al ternero por efectos de palatabilidad. Con el propósito de generar un avance en la consideración de generar bancos de calostros en un futuro, se tuvo en cuenta la temperatura usada comúnmente por los predios, los cuales son colocados en la nevera $\left(8^{\circ} \mathrm{C}\right)$, manteniendo la temperatura interna de los calostros a $10^{\circ} \mathrm{C}$ durante las 168 horas de evaluación del presente método, en la Figura 20 se muestra la dinámica de las variables analizadas en el tratamiento refrigerado a las diversas horas, las cuales no presentaron diferencias apreciables. 
En la Figura 21 se presenta el comportamiento de las variables evaluadas durante las horas de almacenamiento, con la adición del ácido propiónico lo que provocó una disminución del pH inicialmente (de 6.12 a 5.52) y siguió disminuyendo gradualmente en cada medición hasta 4.55 en la hora 36.

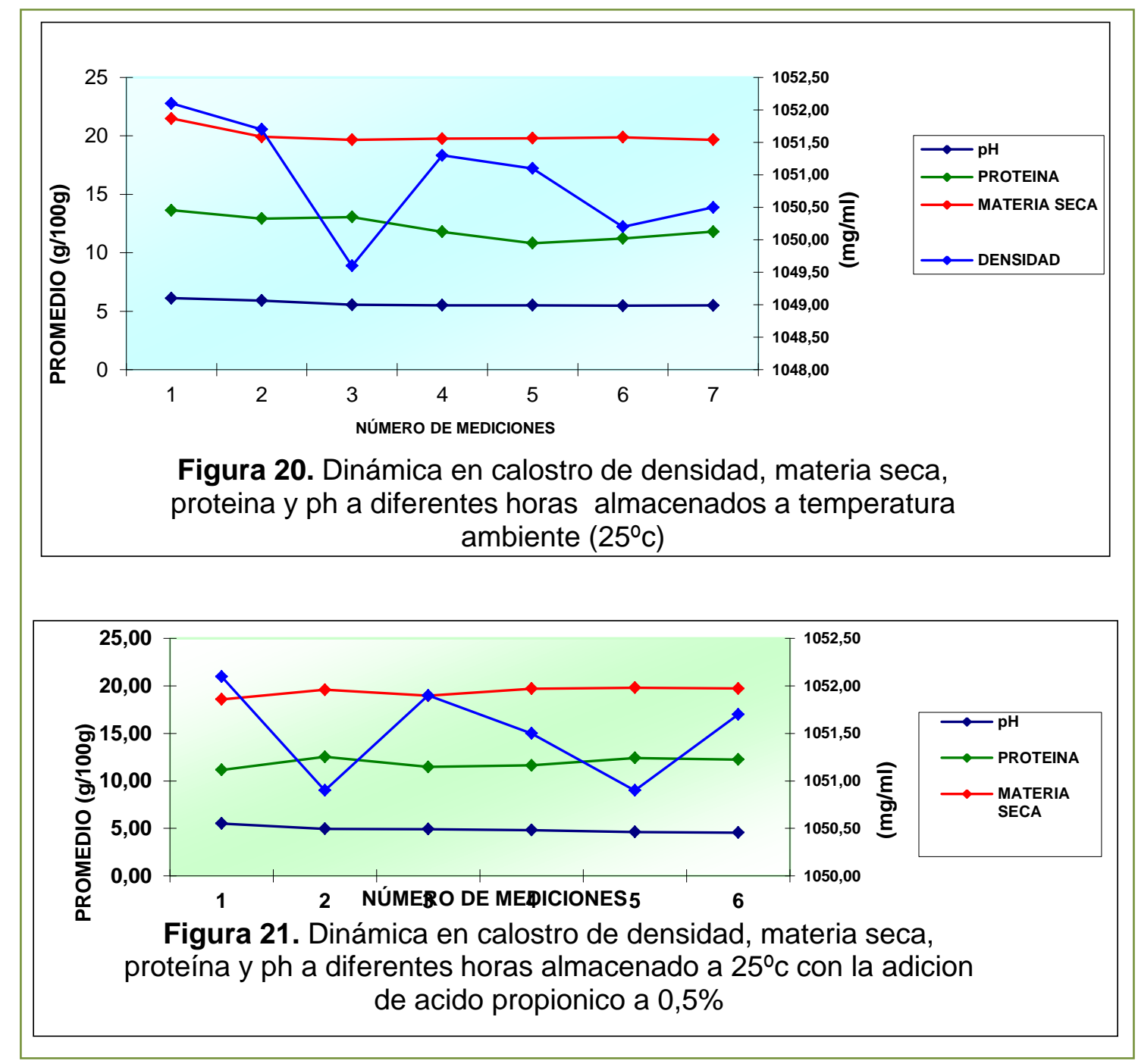

Método de conservación refrigerado. Las variables densidad, materia seca, proteína y $\mathrm{pH}$ no presentaron $(\mathrm{P}>0.05)$ variaciones importantes en las horas de evaluación (Figura 22).

Método de conservación congelado. Por reportes de literatura, este es el mejor método de almacenar calostro, y el presente estudio arrojo los resultados 
esperados referentes al anterior planteamiento, lo cual fue comprobado al no presentar diferencias entre las variables analizadas durante los 30 días de almacenamiento. Sin embargo, el mantener el calostro a bajas temperaturas por un período prolongado de tiempo por el efecto del congelamiento se cristaliza, como consecuencia, las células blancas principalmente linfocitos son afectadas por rompimiento de sus membranas, por consiguiente, pierden su funcionalidad. (Quigley, 1998), en la Figura 23 se observa los comportamientos de las variables a las diferentes horas de análisis.

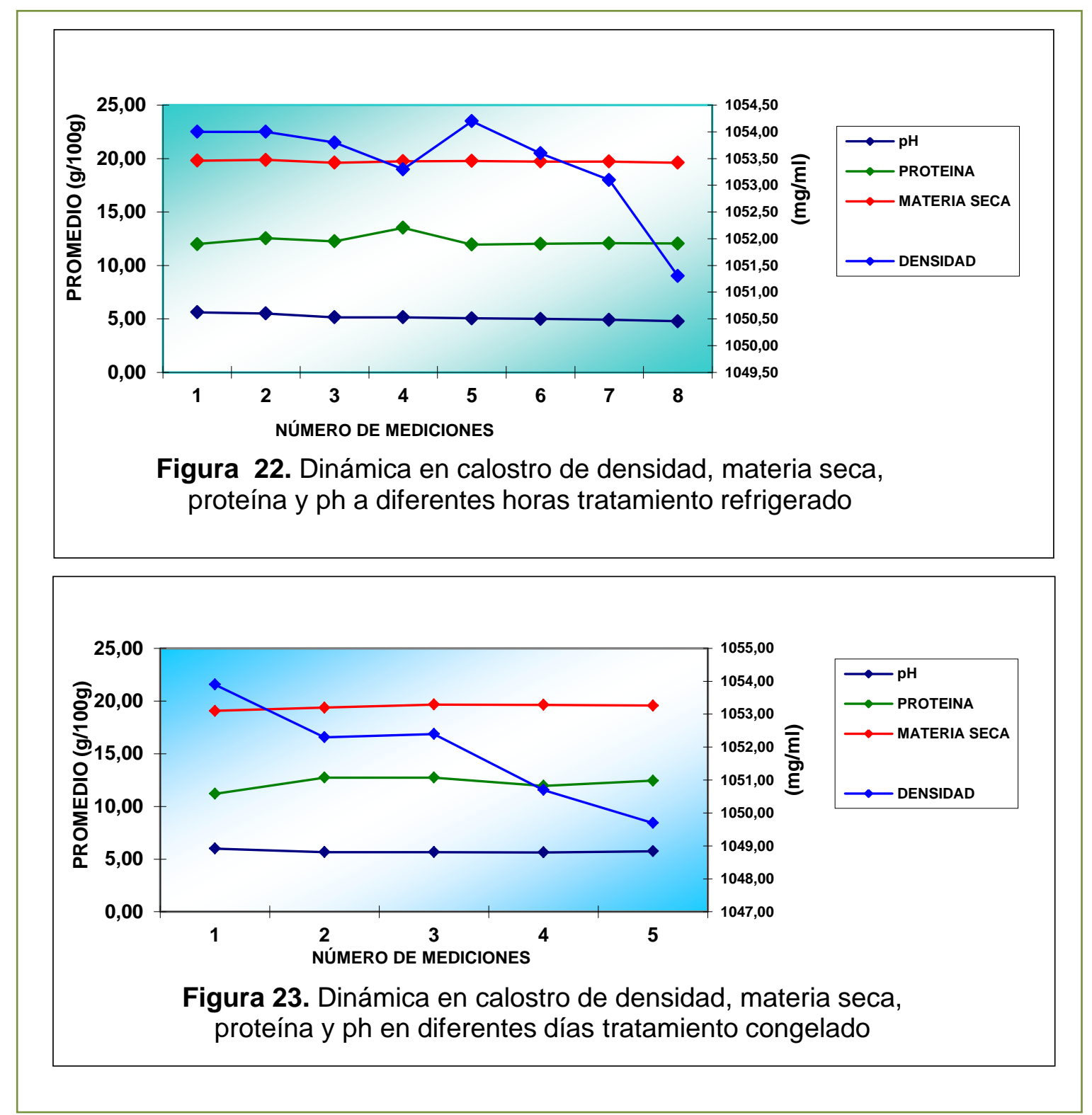




\section{CONCLUSIONES}

El calostro de vacas doble propósito de dos predios del Piedemonte del Meta presentó valores que se encuentran dentro de los reportados en diferentes estudios en lechería especializada de zonas templadas. También se demostró un valor inmunológico de $6923 \mathrm{mg} / \mathrm{dL}$, por lo tanto, el volumen administrado al ternero depende de la concentración de las Ig en las primeras dos horas de vida, de tal forma que calostros con densidades que se encuentren entre los rangos 1061.5$1089 \mathrm{mg} / \mathrm{ml}$ se requiere consumir entre 2.5 litros, y los que están entre 1033.51061 requiere un consumo de 3.0 litros

La utilidad inmunológica y nutricional que ofrece el calostro, es también importante, ya que se pueden aprovechar como suplemento a terneros menores de 4 meses a una dilución final de 1 en 3 , es decir a cada litro de calostro adicionar 2.0 litros de agua, obteniendo una concentración de proteína de 3.87\%, esto es para calostros con densidades menores a $1061 \mathrm{mg} / \mathrm{ml}$ y para los que presenten una densidad superior a 1061 la dilución corresponde a 1 en 3.5 y así obtener una concentración de proteína de $3.62 \%$ porcentaje similar al de la leche en vacas del sistema doble propósito (3.41\%).

Se encontró una correlación positiva $(\mathrm{P}<0.01)$ de densidad con concentración de Ig totales, Ig $G_{2}$, materia seca, proteína total, cenizas y GGT. De igual manera, materia seca esta correlacionada con proteína total y GGT $(P<0.01)$ y proteína total con cenizas $(P<0.01)$, pero al realizar la función de dependencia el modelo no ajusto. Sin embargo, es preciso realizar estudios adicionales similares para hacerlo, que en estudios internacionales han reportado un valor más alto en la función de dependencia, por lo menos en el caso de la concentración de lg totales en función de la densidad del calostro.

El calostro almacenado por un tiempo de 10 horas (temperatura ambiente $25^{\circ} \mathrm{C}$ ) es útil para la alimentación de terneros neonatos si en las primeras 2 horas no ha logrado ingerir calostro de la ubre, igualmente, se puede emplear como refuerzo 
inmunológico si éste es de buena densidad (>1.057 g/ml) en caso contrario, se puede emplear como complemento nutricional. Lo mismo aplica para calostros acidificados, refrigerados y congelados por lo menos durante los tiempos analizados en este trabajo

\section{RECOMENDACIONES}

El promedio de peso al nacimiento en terneros en fincas del sistema doble propósito es de $27 \mathrm{~kg}$. Con base en la media de lg totales determinados en este estudio (6923 $\mathrm{mg} / \mathrm{dL}$ y una densidad promedio de $1.057 \mathrm{~g} / \mathrm{ml}$ ) se recomienda suministrar a los terneros una cantidad mínima de 1.6 litros de calostro (del primer ordeño en lo posible) antes de las 2 primeras horas de nacido, teniendo en cuenta que un ternero neonato con este peso debe absorber como mínimo $21.6 \mathrm{~g}$ de $\mathrm{lg}$ totales del calostro; es decir, $8 \mathrm{mg} / \mathrm{ml}$ de sangre circulante en su organismo.

Profundizar en la investigación y estandarización de bancos de calostro en cuanto a la valoración de la calidad microbiológica, ampliación de tiempos de lectura en especial del tratamiento en fresco, y en la utilización de otros ácidos débiles preservantes o sus sales, con el fin de ajustarlo a las necesidades y beneficios del productor.

\section{REFERENCIAS BIBLIOGRÁFICAS}

1. AOAC. Official Methods of Analysis $\left(18^{\text {th }}\right)$ Association of Official Analytical Chemists, Arligton, V. A. Washington, D.C. 2006.

2. Aricada H., Bedoya R., García A., Heredia C., Peláez C., Ceballos A. Competencia inmunológica en la primera semana de vida en terneros mantenidos bajo dos sistemas de producción de leche. Rev Col Cienc Pec., 17 (2): 167-174. 2004.

3. Barrington G. M., Mc Fdden M. T., Besser T. E. Regulation of colostrogenesis in cattle. Livestock Production Science, 70: 95-104. 2001.

4. Castro P., Elizondo J. Crecimiento y desarrollo ruminal en terneros alimentados con iniciador sometido a diferentes procesos. Agron. Mesoam., 23 (2): 343-352. 2012. Disponible En: http://www.scielo.sa.cr/scielo.php?script=sci arttext\&pid=S1659132120120002 $\underline{00013 \& \operatorname{lng}=\mathrm{es} \& \mathrm{nrm}=\mathrm{iso}}$ 
5. Escobar A., Bonilla R. Factores de manejo que afectan la morbilidad y mortalidad en terneros durante los 3 primeros meses de vida en el municipio de San Pedro de los Milagros, Departamento de Antioquia. Trabajo de Grado. Facultad de Medicina Veterinaria y Zootecnia. Universidad Nacional de Colombia. 1997.

6. Fleenor W. A., Stott G. H. Hydrometer test for estimation of immunoglobulin concentration in bovine colostrum. Journal Dairy Science, 63: 973. 1980.

7. Flórez H. Manejo sanitario del ternero neonato. En memorias curso alternativas para mejorar la producción pecuaria en los departamentos del Meta y Guaviare. Corpoica-Plante. C.I. La Libertad. p 7-18. 1998.

8. Flórez, H. Importancia y uso del calostro en bovinos. Boletín técnico Corpoica. 30 (4): 1-8. 2000.

9. García J, Albornoz O, Vela D. Determinación de inmunoglobulinas séricas de origen calostral en terneros recién nacidos. Ser. Zool. Bol. Téc. 6, 2: 77-85. 2006.

10. Gómez, M. Morbilidad y mortalidad de terneros menores de tres meses de edad en cinco fincas del Piedemonte Llanero. Trabajo de Grado. Facultad de Medicina Veterinaria y Zootecnia. Universidad de los Llanos. 1999.

11. Hadorn U., Blum W. Effects of feeding colostrum, glucose or water on the first day of life on plasma immunoglobulin G concentrations and Gamma Glutamyl transferase activities in calves. Journal Veterinary Medicine Association, 44: 531-537. 1997.

12. Hernández T., Olaya B. Caracterización inmunológica y generación de banco de calostro en explotaciones doble propósito en el Piedemonte llanero. Tesis de grado. Medicina Veterinaria y Zootecnia. Universidad de los Llanos. Villavicencio, Meta, 2004.

13. IDEAM. Instituto de Hidrología, Meteorología y Estudios Ambientales. Sistema de Información Nacional Ambiental. Estación "La Holanda" Municipio de Granada (Meta). 2004.

14. Lakritz J., Tyler J. W., Hostetler D. E., Marsh A. E., Weaver D. M., Holle J. M. Effects of pasteurization of colostrum on subsequent serum lactoferrin concentration and neutrophil superoxide production in calves. Journal American Veterinarian Research, 61 (9): 1024. 2000.

15. López M., Melo J., Donado M. P., Oliver. Factores que afectan la morbilidad y la mortalidad en terneros de carne y de doble propósito durante los tres primeros meses de vida en la altillanura colombiana. Trabajo de Grado. Facultad de Medicina Veterinaria y de Zootecnia Universidad Nacional de Colombia. 1998.

16. ICN Biomedical. Technical Information. Quantitative determination of bovine IgA, IgM and IgG2. Catalog number: 64474, 64473, 64470. 2003.

17. Martínez G., Romero A., Donado M. P., Flórez H. Viabilidad, inmunidad pasiva y mortalidad de terneros de vacas doble propósito en fincas del caribe colombiano. World Biatrics Congress. Punta del Este, Uruguay. Book of Abstracts. 94 p. 2000. 
18. Parra, J. L. Modelo de asistencia integral pecuaria para pequeños y medianos productores del sistema doble propósito del Piedemonte Llanero. Informe final. Corpoica-Pronatta. 96: 142-147. 2003.

19. Perez E., Noordhuizen J., Van Wuiskhhuise L., Stassen E. N. Management factors related to calf morbidity and mortality rates. Livestock Production Science, 25: 79-93. 1990.

20. Perino L. J., Wittum T., Gary R. Effects of various risk factors on plasma protein and serum immunoglobulin concentrations of calves at postpartum hours 10-24. Journal American Veterinarian Research, 56 (9): 1144-1148. 1995.

21. Perino L. J. A guide to colostrum management in beef cows and calves. Veterinary Medicine. Food Animal Practice, 75-81. 1997.

22. Quigley J. Usando el calostrómetro para medir la calidad del calostro. No. 22: 1-3. 2000. Disponible En: www.americanprotein.com/calf/calfnotes.com

23. Robinson J. D., Stott G. H., Denise S. K. Effects of passive immunity on growth and survival in the dairy heifer. J. of Dairy Sci., 71 (5): 1283-1287. 1998.

24. Sivula N., Ames T., Marsh W., Werdin R. Descriptive epidemiology of morbidity and mortality in Minnesota dairy heifer calves. Preventive Veterinary Medicine, 27: 155-171. 1996.

25. Stott G. H. Immunoglobulin absorption in calf neonates with special considerations of stress. Journal Dairy Science, 63 (4): 681-688. 1980.

26. Vann R. C., Holloway J. W., Carstens G. E., Boyd M. E., Randel R. D. Influence of calf genotype on colostral immunoglobulins in Bos taurus and Bos indicus cows and serum immunoglobulins in their calves. Journal Dairy Science, 73: 3044-3050. 1995.

27. Virtala L. Mechor G. D., Grohn Y. T., Erb H. N. Morbidity from non-respiratory diseases and mortality in dairy heifers during the first three months of life. Journal of American Veterinary Medical Association. 208: 2043-2046. 1996.

28. Wattiaux, M. A. Importancia de alimentar con calostro. Instituto Babcock para la Investigación y Desarrollo Internacional de la Industria Lechera. Universidad de Wisconsin - Madison. Boletín №. 28: 109-112. 2001. 